\title{
Properties of Voltage-Dependent Somatic Stiffness of Cochlear Outer Hair Cells
}

\author{
David Z.Z. He And Peter Dallos \\ Auditory Physiology Laboratory (The Hugh Knowles Center), Departments of Neurobiology and Physiology and Communication \\ Sciences and Disorders, The Institute of Neuroscience, Northwestern University, Evanston, IL 60208 USA
}

Received: 28 December 1999; Accepted: 30 March 2000; Online publication: 19 July 2000

\begin{abstract}
We have shown recently that isolated cochlear outer hair cells change their axial stiffness when their membrane potential is altered under voltage-clamp. Here we extend those observations, using a more stable mechanical platform, the microchamber, to hold the cells and to deliver voltage commands. Cell stiffness is determined by opto-electronically measuring the amplitude of motion of a flexible fiber as it is loaded by the cell. Cell stiffness is decreased by depolarization and increased by hyperpolarization. The stiffness changes have been measured with sinusoidal electrical command signals up to $1750 \mathrm{~Hz}$ and fiber motion up to $2000 \mathrm{~Hz}$. It is shown that electrically evoked stiffness changes and length changes (electromotility) have very similar characteristics and may arise in a common process.
\end{abstract}

Keywords: outer hair cell, cochlear mechanics, micromechanics, cell stiffness, microchamber, gadolinium

\section{INTRODUCTION}

Cochlear outer hair cells (OHCs) are sensory receptor cells that acquired motor capability (Brownell et al. 1985). The membrane potential-dependent motor process (Ashmore 1987; Santos-Sacchi and Dilger 1988) is said to provide mechanical feedback to the

Correspondence to: Dr. Peter Dallos $\bullet$ Northwestern University 2299 North Campus Drive $•$ Evanston, IL 60208. Telephone: (847) 4913175; fax: (847) 467-4327; e-mail: p-dallos@northwestern.edu basilar membrane-tectorial membrane complex of the cochlea. This amplification process is apparently responsible for high sensitivity, broad dynamic range, exquisite frequency resolution, and a host of nonlinear behaviors evident in the normal mammalian ear (for reviews see Dallos, 1992, 1996). It is possible that OHCs alter the mechanical impedance of the cochlear partition (Kolston et al. 1990). In this case, one would expect a voltage-dependent stiffness change to occur in OHCs. This somatic stiffness change, in turn, would modulate the stiffness of the cochlear partition (Allen 1990). Discussions of the relative stiffness of OHCs versus that of the basilar membrane appear in Russell and Schauz (1995) and He and Dallos (1999). Briefly, available data indicate that the axial stiffness of OHCs is considerably less than the stiffness of the basilar membrane. If correct, it would not be possible for OHC stiffness to constitute a significant factor in the total stiffness of the cochlear partition. It is noted, however, that if this stiffness disparity existed, OHC motility could not materially influence basilar membrane motion either. The relationship between basilar membrane and OHC stiffness needs to be considered unresolved.

It is the purpose of this work to examine putative stiffness modulation of outer hair cells. We have reported preliminary results before (He et al. 1997), as have others (Frolenkov et al. 1998). Data obtained with a different technique from that used here have also been published (He and Dallos, 1999).

Outer hair cells outnumber the true sensory receptors of the mammalian ear-the inner hair cells-by approximately $4: 1$. They have sparse afferent connections, consisting of thin, unmyelinated fibers that are unlikely to carry information about the time and amplitude structure of acoustic signals. These cells 
do, however, receive a prominent efferent innervation from the medial olivocochlear system in the form of large terminals forming predominantly cholinergic synapses (for reviews, see Guinan 1996; Sewell 1996). The cells are cylindrical with fairly uniform diameter of $\sim 9 \mu \mathrm{m}$ and with lengths graded along the cochlea from $20 \mu \mathrm{m}$ at the high-frequency basal end to as long as $100 \mu \mathrm{m}$ at the low-frequency apical end (for reviews, see Holley 1996; Slepecky 1996). The cells possess an elaborate and highly structured cortical network of actin and spectrin filaments sandwiched between the plasma membrane and concentric layers of endoplasmic reticula, known as the subsurface cisternae (see review by Holley 1996). The density of integral membrane proteins in the lateral plasma membrane is also unusually high, $\sim 6000 / \mu \mathrm{m}^{2}$ (Forge 1991, Kalinec et al. 1992). These $\sim 11$-nm-diameter molecules are considered to be the motors whose concerted voltagedependent conformational change is assumed to be funneled into axial elongation/contraction cycles of the cell via the cortical network (Holley and Ashmore 1988; Dallos et al. 1992; Kalinec et al. 1992). These putative conformational changes require neither $\mathrm{Ca}^{2+}$ nor ATP (Holley and Ashmore 1988) and can occur at microsecond rates (Dallos and Evans 1995).

The static axial stiffness of OHCs has been measured previously (Holley and Ashmore 1988; Zenner et al. 1992; Gitter et al. 1993; Hallworth 1995, 1997; Iwasa and Adachi 1997; Ulfendahl et al. 1998). Static stiffness was also manipulated by various means. Russell and Schauz (1995) showed that axial stiffness decreases when salicylate is applied to the cell, while Hallworth (1997) found that force generation by his cells was reduced. Dallos et al. (1997) demonstrated that delivery of the efferent neurotransmitter acetylcholine (ACh) to the cell's synaptic pole also decreased the axial stiffness. While salicylate decreases the electrically evoked motile response of the cells, ACh increases it.

The axial stiffness is related to the OHCs' internal turgor pressure. Several investigators studied modifications of cell turgor and its influence on the cell's electromotile response (Holley and Ashmore 1988; Shehata et al. 1991; Tunstall et al. 1995; Housley et al. 1995; Kakehata and Santos-Sacchi 1995; Hallworth 1997). In general, changes in turgor are a consequence of osmotic imbalance between the cell's interior and the surrounding medium. Turgor changes also result from applying the whole-cell patch configuration to OHCs (Santos-Sacchi 1991); in this case, the cells generally deflate.

In these experiments stiffness was measured with the driven fiber method (Strelioff and Flock 1984), and the cells were stimulated in themicrochamber (Evans et al. 1989; Fig. 1a).

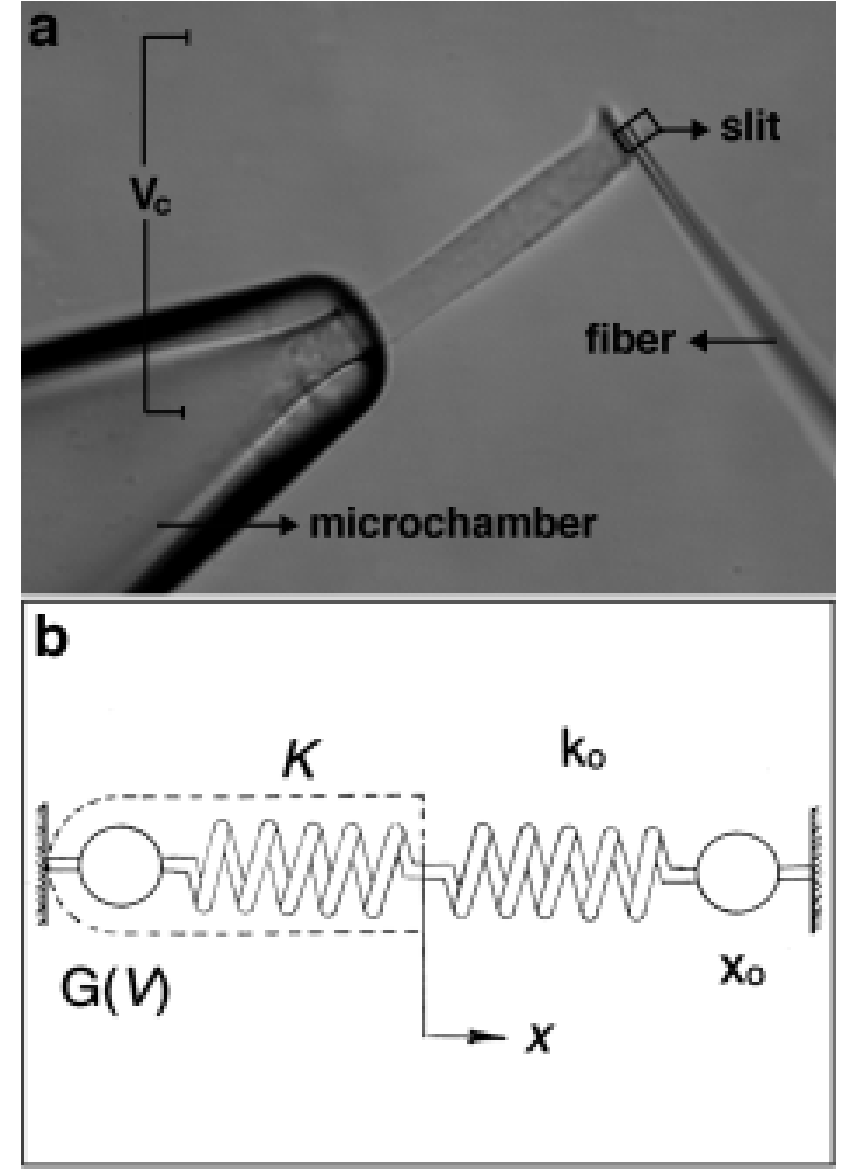

FIG. 1. (a) Video image of an outer hair cell in a microchamber with the tip of a driven glass fiber apposed to the ciliated apical pole of the cell. Only the proximal tip of the fiber is shown; it is connected at its distal end to a piezo bimorph. The tip of fiber is imaged onto a photodiode through a rectangular slit. Voltage commands $\left(V_{c}\right)$ are imposed between the inside of the microchamber and the surrounding fluid medium. (b) Equivalent mechanical circuit representation of the cell and the driven fiber. The aggregate of the putative molecular motors that produce cell contraction and elongation in response to voltage commands $\left(V_{c}\right)$ is modeled by the displacement source $G(V)$. The displacement $G(V)$ represents the unloaded ("open circuit") motile response of the cell. The displacement $x_{0}$ produced by the piezo bimorph upon the distal end of the fiber is signified by the displacement source. The total axial stiffness of the cell is $K$, while the stiffness of the fiber is $k_{0}$. The displacement measured by the photodiode is $x$. In the microchamber configuration, the voltage delivered to the cell $(V)$ is not the same as the command voltage $\left(V_{c}\right)$. Inasmuch as the inside and outside cell-membrane segments act as a voltage divider, the effective driving voltage of motility is less than the command voltage $V_{c}$ (Dallos et al. 1991; 1993; see also Appendix 2).

\section{METHODS}

\section{Hair cell preparation}

Pigmented guinea pigs (weight range: 150-300 g) were anesthetized with an overdose of sodium pentobarbital. The cochleae were dissected and kept in cold 
tissue culture medium (Leibovitz's L-15). The organ of Corti was isolated from second, third, and fourth turns of the cochlea. After brief enzymatic digestion $(1 \mathrm{mg} / \mathrm{mL}$ type IV Collagenase, Sigma, St. Louis, MO), cells were transferred to small plastic chambers filled with enzyme-free culture medium. Solitary cells were obtained after gentle trituration. The normal medium was Leibovitz's L-15 (Gibco), supplemented with 15 mM HEPES and adjusted to $\mathrm{pH} 7.35,300-310$ mOsm (inorganic components in mM: $\mathrm{NaCl} 136 ; \mathrm{NaH}_{2} \mathrm{PO}_{4}$ 5.8; KCl 5.4; $\mathrm{CaCl}_{2} 1.3 ; \mathrm{MgCl}_{2} 0.9 ; \mathrm{MgSO}_{4}$ 0.4). All experiments were performed at room temperature. Animal handling and care procedures were approved by the Northwestern University Institutional Review Board and the NIH.

\section{Microchamber method}

Healthy-appearing isolated OHCs (no obvious signs of granularity, no swelling, and no nucleus translocation) were gently drawn into a close-fitting glass pipette, the microchamber (Evans et al. 1989, 1991), with their synaptic poles inside (Fig. 1a). The microchamber was fabricated from 2-mm thin-wall glass tubing (A-M Systems, Carlsborg, WA) by a two-stage microelectrode puller (Narishige, Tokyo, Japan) and heat-polished to an aperture diameter close to that of a hair cell $(\sim 9$ $\mu \mathrm{m})$. The microchambers, filled with normal medium, had electrical resistances of approximately $0.4-0.5$ $\mathrm{M} \Omega$. The microchamber was mounted in an electrode holder that was controlled by a 3-D micromanipulator (Leitz, Wetzlar, Germany). The position and height of the microchamber in the bath was readily adjustable with the micromanipulator. Cells in the bath could be picked up easily and drawn into the microchamber by gentle suction. The experimental bath, which contained the isolated OHCs, was placed on the stage of an inverted microscope (Zeiss, Oberkochen, Germany). $\mathrm{A} \mathrm{Ag} / \mathrm{AgCl}$ ground electrode was installed in the bath. The microchamber was connected to the voltage-command generator by a $\mathrm{Ag} / \mathrm{AgCl}$ wire. The suction port of the microchamber holder was connected to a micrometer-driven syringe to provide negative or positive pressure in order to draw in or expel the cells. The inserted cell and the microchamber formed a resistive seal (4-5 M $\Omega$ ) that was mechanically stable.

Transcellular potentials $\left(V_{c}\right)$ were applied across the microchamber. Negative voltage commands made the bath negative relative to the inside of the microchamber, resulting in the depolarization of the excluded cell membrane segment and hyperpolarization of the included cell membrane segment (Dallos et al. 1991). Voltage-command stimuli (usually 100-mV peak) were generated by a programmable generator in an IBM PC-compatible computer, which also contained the data acquisition hardware. See Appendix 2 for a discussion of the relationship between command voltage and membrane potential of the excluded cell segment.

\section{Displacement measurement}

Cell motility and fiber motion were measured by a photodiode system. The magnified image of the cell's ciliated pole and the fiber or the fiber alone (loaded vs. unloaded) was projected onto the photodiode through a rectangular slit. The position of the slit in front of the photodiode was adjustable so that the image of the object could always be projected onto the photodiode without moving the cell or the fiber. The position of the image in the slit was monitored by a video camera behind it. The image of the entire cell was also obtained by a second video camera and displayed throughout the experiment. Cell-length changes or fiber displacements were measured by changes in the current of the photodiode. The photocurrent response was calibrated to displacement units by moving the slit by a fixed distance with the image of the cell (or fiber) in front of the photodiode at the beginning of each trial. It was possible to measure displacements up to $\sim 3000 \mathrm{~Hz}$ with the photodiode-measuring system (3-dB cutoff frequency: 1100 $\mathrm{Hz})$. Frequency response data were compensated for the characteristics of the photodiode system. For measuring low-frequency responses, five averages were preset for each trial, whereas for measuring highfrequency responses, 100 averages were preset. The noise floor in averaged, Fourier-transformed data was approximately $6 \mathrm{~nm}$.

\section{Stiffness measurement}

Glass fibers were pulled from 1.5-mm glass tubing by a microforge (Stoelting, Chicago, IL). The tapered tip of a fiber was usually $4-5 \mathrm{~mm}$ in length and 2-3 $\mu \mathrm{m}$ in diameter. With these dimensions, it was expected that the stiffness at the tip of the fiber was somewhat less than that of the cells. The glass fiber was attached to an electrical piezo actuator, which was mounted on a 3-D Narishige micromanipulator. The experimental arrangement for stiffness change measurement is illustrated in Figure 1a. OHCs were 15-30\% inserted into the microchamber and the tip of the glass fiber was brought against the ciliated pole of the cells, using the 3-D micromanipulator, so that the cell and fiber were approximately perpendicular. The fiber was placed transverse to the OHC's long axis in such a way that the fiber's lateral motions would compress or relax the cell. It was important that the fiber compress the cell somewhat prior to setting the fiber or cell into 
motion since, if it were not preloaded, the fiber could be detached from the cell when the cell contracted. For additional discussion of loading the fiber unto the cell and effects due to loading, see Appendix 1.

Unloaded motility, loaded motility, free-fiber motion, and fiber-driven cell motion were measured. Various types of stimuli were delivered to the cell and fiber, depending on the nature of the experiments. The details of the various stimulus scenarios are described in the Results section.

Data analysis, consisting of high- and low-pass digital filtering and computation of Fourier spectra, was performed with Igor Pro (WaveMetrics, Inc., Lake Oswego, OR), while simulations were produced with Mathematica (Wolfram Research, Inc., Champaign, IL). Both programs were run on a Power Macintosh G3 platform. Prior to computing Fourier spectra, the waveforms were windowed with the built-in Hanning window of Igor Pro.

\section{Calibrations}

Sinusoidal voltage bursts at $100 \mathrm{~Hz}$ were applied to the bimorph and the displacement of an attached glass fiber was measured. From the steady-state portion of these data, a linear relationship between the command voltage to the bimorph and the recorded fiber displacement was demonstrated. This linearity extends over a range well in excess of the displacements actually measured during experiments. Also from the steady-state portion of the waveforms, a measure of symmetry is derived as the difference between positive and negative half-cycles divided by the peak-to-peak amplitude and expressed as a percentage. The maximum asymmetry was approximately $1 \%$ throughout the amplitude range.

In Figures 3c, $\mathrm{f}$ and $4 \mathrm{~b}, \mathrm{c}$, examples of the Fourier spectra of loaded fiber motion are given when a 100$\mathrm{Hz}$ signal is used to drive the bimorph and the cell functions as a passive load. These spectra contain significant components only at the $100-\mathrm{Hz}$ input frequency.

One of the greatest potential problems with these experiments is the necessity to maintain adequate contact between the driven fiber and the cell throughout a given measurement series. Consider that, if contact were not secure, the cell would present a different load to the fiber as contact was made or lost, as a result of the combined displacement pattern of fiber and cell. In other words, when fiber and cell move toward one another (because of the motion of either), the stiffness load on the fiber is present; whereas if they move apart, the load could be absent. This nonlinearity (rectification) could simulate the phenomenon whose presence we are testing. Waveforms and spectra produced by this coupling-decoupling process are not easy to distinguish from those produced by a true voltage-dependent or length-dependent stiffness of the cell (Fig. 2c and 2d vs. 2f). It is further considered, however, that the coupling-decoupling mechanism would not operate as long as the fiber exerts a significant force on the cell and vice versa throughout the stimulus cycle. This can be ascertained from two measures. First, a prerequisite for coupling obtains from a simple comparison of loaded-fiber motion $(x)$ and free-fiber motion $\left(x_{0}\right)$ in terms of the fiber's $\left(k_{0}\right)$ and the cell's $(K)$ stiffnesses. This relation is expressed as $\zeta$ in eq. (1):

$$
\zeta=\frac{x}{x_{0}}=\frac{k_{0}}{k_{0}+K}
$$

As long as the two "springs" are at least partially coupled, $\zeta<1$; if they become decoupled, $\zeta=1$. The average $\zeta$ was 0.323 in the entire experimental series. The most sensitive indicator that the modulation is not a result of coupling-decoupling of the fiber is a lack of measurable second harmonic of the fibermotion frequency in the loaded-motion spectrum (see Theoretical Results below). In our experimental series we did encounter cases where this second harmonic was present. Data from those experiments were not used. Otherwise, the only cases when a second harmonic was present were those rare instances when the unloaded fiber response itself possessed significant second harmonic content.

To assure the stability of the cell in the microchamber, specifically, to rule out its slippage at the chamber's orifice, control experiments were conducted. These are described in some detail in Appen$\operatorname{dix} 3$.

Stiffness of glass fibers was calibrated by the "string instrument" method, described in detail by Zwislocki and Cefaratti (1989). The fibers used in this experimental series ranged in stiffness from 2.6 to $8.6 \mathrm{mN} / \mathrm{m}$.

\section{Stiffness vs. damping changes}

As seen below, all our results are interpreted in terms of changes in the cell's internal axial stiffness. It is legitimate to ask whether there is reasonable justification for this choice. In other words, do we know that changes in the cell's internal damping might not play a significant role? We addressed this issue before (Dallos et al. 1997) in another context and dismissed the cell's internal damping as a quantity that would not significantly influence the cell's motile response at low audio frequencies. We contended that the stiffness reactance dominates the cell's dynamic response at low audio frequencies. Here this issue is re-addressed with the aid of data available from the present experiments. If the cell's mechanical input impedance (that presented to the driving fiber) is stiffness-dominated, 
a. Input waveforms
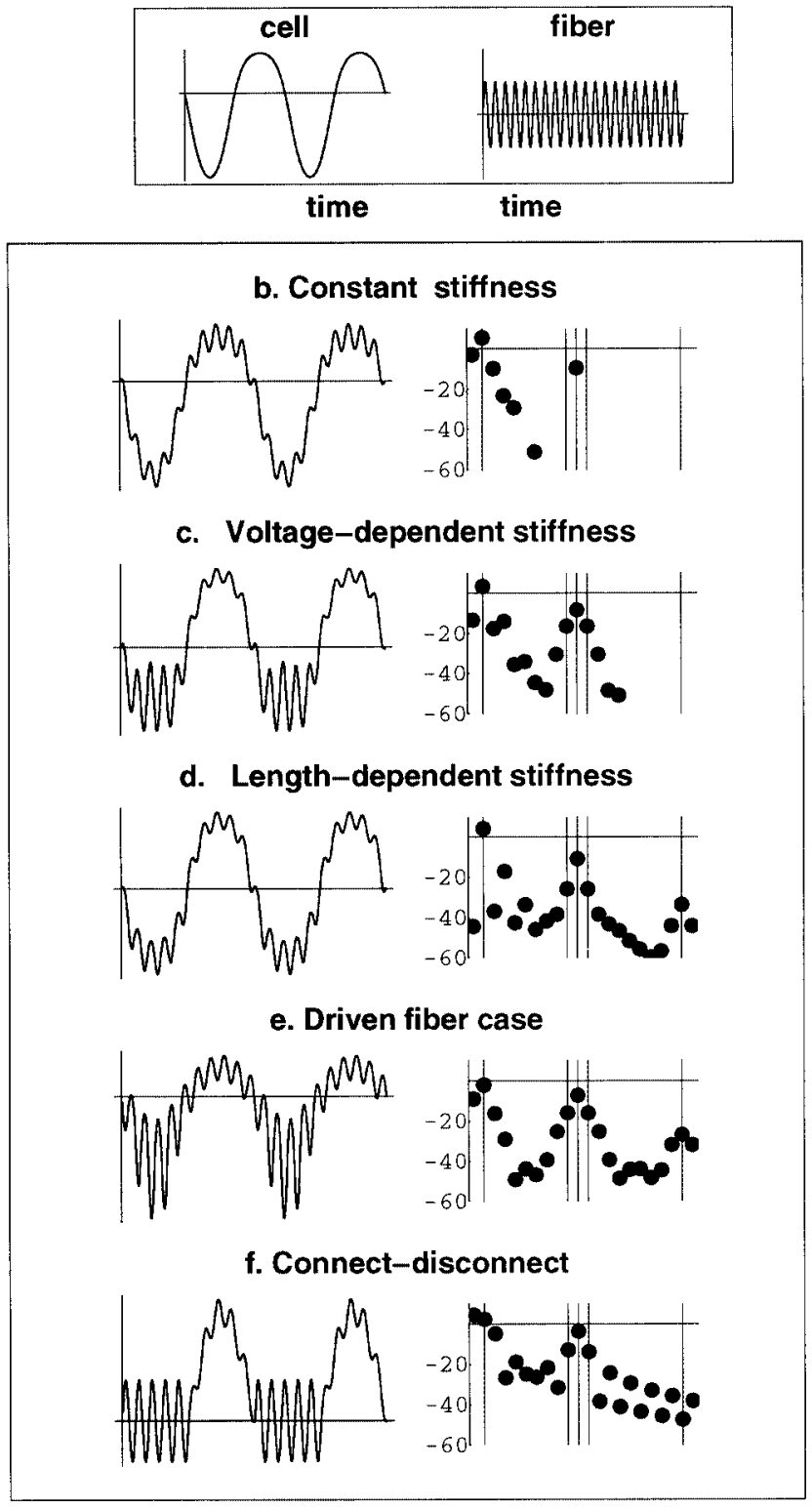

time

frequency

one does not expect a phase shift between unloaded and loaded fiber displacements. If the fiber's stiffness is $k_{0}$, while that of the cell is $K$, then loaded fiber motion is expected to be a fraction of the free fiber motion that was given in Eq. (1). The fraction $\zeta$ in Eq. (1) is a real number in this case. If, however, the cell has significant internal damping, a phase shift is expected at some frequency. Under such conditions, a combined stiffness-damping impedance needs to be substituted in place of $K$ in Eq. (1). The fraction $\zeta$ becomes complex:

$$
\zeta(j \omega)=\frac{k_{0}}{k_{0}+K_{1}}+\left(\frac{j \omega R}{k_{0}+K}\right)^{-1}
$$

where the cell's internal resistance is $R$ and $\omega=2 \pi f$.
FIG. 2. Illustrations of theoretical results. (a) The two unloaded displacements used in the computational scheme: (left) electromotile response of the cell, $G(V)$, to a sinusoidal voltage command $V_{c}$, assuming that $G(V)$ represents a Boltzmann process as in eq. 3; (right) sinusoidal displacement of free fiber, $x_{0}$. The two frequencies are as in the majority of our experiments: The voltage command to the cell is at $10 \mathrm{~Hz}$, while that to the bimorph is at $100 \mathrm{~Hz}$. In all cases the amplitude ratio of the sinusoids $x_{0}$ and $V$ are $1: 2$. Furthermore, in all cases $k_{0}$ is taken as one-half the static value of the cell's stiffness. The remaining panels include computational results showing waveforms (left) and spectra (right) obtained under various assumptions. The vertical lines along the frequency axes in all spectra are at $f_{c}=$ $10, f_{0}-f_{c}=90, f_{0}=100, f_{0}+f_{c}=110$, and $2 f_{0}=200 \mathrm{~Hz}$. Vertical scale for all spectra is in decibels re the amplitude of free-fiber motion. Spectra are computed from time records of ten cycles even though only two cycles are shown in the left panels for clarity. (b) Linear system: simple addition of the two signals with the resulting displacement being weighted by the two stiffnesses (as in eq. 2). The spectrum includes a series of low-frequency components, which are a consequence of the nonlinearity of cell displacement due to the Boltzmann relationship. In addition, there is a $100-\mathrm{Hz}$ component reflecting the fiber motion. There is no intermodulation or second harmonic of $f_{0}$. (c) Here the assumption is that the cell's axial stiffness is voltage dependent, as in eq. 5. Modulation is detectable as changes in the amplitude of the fiber motion (seen in the waveform) and as intermodulation components (seen in the frequency spectrum). The intermodulation components are at 90 and $110 \mathrm{~Hz}$, but other components are seen at other frequencies around $100 \mathrm{~Hz}$ because the various higherfrequency components that represent cell motion (e.g., $20 \mathrm{~Hz}, 30$ $\mathrm{Hz}$, etc.) also intermodulate with the $100-\mathrm{Hz}$ fiber motion. There is no $2 f_{0}$. (d) Simulation of cell-length-dependent stiffness as in eq. 6 . It is evident that this form of nonlinearity again produces a complex waveform and complex spectrum, including $2 f_{0}$. (e) Simulation of the experiment where no electromotility is induced, but both lowand high-frequency sinusoidal signals are fed to the bimorph. It is assumed that the cell's stiffness changes according to its length (eq. 6) which is expressed in eq. 7 . There is significant intermodulation between harmonics of the lower frequency and both $f_{0}$ and $2 f_{0}$. (f) Simulation of inadequate coupling between fiber and cell while no other nonlinear effects are present. The coupling-decoupling process is simulated by removing the cell's stiffness load from the fiber on alternate half-cycles of the cell's displacement. It is assumed that $G(V)>x_{0}$, hence decoupling is only simulated for cell movement. It is apparent from both waveform and spectrum that in this case there is again a rich spectrum, containing all harmonics of the coupling-decoupling frequency.

One expects $\pi / 4$ phase shift at the corner frequency, $f=\left(k_{0}+K\right) / 2 \pi R$. Using our approximate average value for $K$ in the quiescent state of $6 \mathrm{mN} / \mathrm{m}$ (He and Dallos 1999), a typical fiber stiffness of $k_{0}=0.5 K$, and the estimate of $R=5 \times 10^{-5} \mathrm{mN} \mathrm{s} / \mathrm{m}$ (Dallos et al. 1997), we found that $f=28,660 \mathrm{~Hz}$. This frequency is above all of those used in the present experiments.

We have computed the phase difference between loaded and free fiber motions for 20 cells where these data were available at $2000 \mathrm{~Hz}$. The average phase shift was $8.5^{\circ}$. From this phase shift, an average corner frequency can be estimated as approximately $13.4 \mathrm{kHz}$. The small phase shift between free- and loaded-fiber motions signifies that damping has minimal effect at the frequencies studied and, more importantly, that 
putative voltage-dependent damping changes (if any) would not account for the experimental results. It is likely that our previous estimate of damping (Dallos et al. 1997), obtained less directly, was low. The cells' internal damping appears to be about twice that estimated previously. From the above numbers, $f=13.4$ $\mathrm{kHz}$ and $K=6 \mathrm{mN} / \mathrm{m}$, one finds $R \approx 10^{-4} \mathrm{mN} \mathrm{s} / \mathrm{m}$. Others have different estimates of the outer hair cell's internal damping. For example, the measurements of Hemmert et al. (1997) suggest that above $200 \mathrm{~Hz}$ the cell no longer behaves as a pure compliance. Tolomeo and Steele (1998) put the cutoff frequency to approximately $3 \mathrm{kHz}$ for cells of similar length as used here. In contrast, Dallos and Evans (1995) placed the corner frequency of cell motility well above their instrumentation limit of $24 \mathrm{kHz}$ and Frank et al. (1999) placed it above $79 \mathrm{kHz}$. This matter needs to be better resolved.

\section{RESULTS}

\section{Theoretical results}

Figure $1 b$ depicts an equivalent mechanical circuit that represents the hair cell-driven fiber system. The circuit is a version of one that was used previously (Hallworth 1995; Russell and Schauz 1995; Dallos et al. 1997; Iwasa and Adachi 1997). The aggregate displacement of the elementary motors produces an electromotile response of the unloaded cell, $G(V)$, in response to the voltage, $V$. The unloaded displacement of the driven fiber is $x_{0}$, and its stiffness is $k_{0}$. The variables $V$ and $x_{0}$ are arbitrary functions of time. The axial stiffness of the cell is $K$. In this formulation, $G(V)$ and $K$ comprise a mechanical equivalent circuit of the cell. Consequently, the combined displacement of the cell and attached fiber is expressed as

$$
x=G(V) \frac{K}{K+k_{0}}+x_{0} \frac{k_{0}}{K+k_{0}}
$$

If one assumes that the internal stiffness of the cell, $K$, is constant, then whatever the spectral content of the two "signals" $\left[G(V)\right.$ and $\left.x_{0}\right]$ might be, the displacement $x$ will contain the simple sum of these spectra. In other words, $G(V)$ and $x_{0}$ will not intermodulate. If, however, $K$ depends on the driving voltage $V$, then the spectrum of $x$ will differ from the simple sum of individual spectra and intermodulation will occur. Finally, even if the stiffness is only indirectly voltage dependent, via cell length, intermodulation is still expected. We examine these cases below.

Figure 2a depicts the unloaded electromotile response of the cell (left) and the unloaded displacement pattern of the fiber (right). The electromotile response is simulated by assuming that cell length is controlled by a change in membrane potential $(V)$ via a Boltzmann process (Santos-Sacchi 1991; Dallos et al. 1992; 1993a). This assumption yields the following relationship between cell displacement $[G(V)]$ and voltage $(V)$, where $a_{0}, a_{1}$, and $a_{2}$ are constants (Dallos et al. 1993a):

$$
G(V)=\frac{a_{0}}{1+\exp \left(-a_{1} V+a_{2}\right)}-\frac{a_{0}}{1+\exp \left(a_{2}\right)}
$$

We first consider the linear case, for which cell stiffness $K$ is a constant. The graph in Figure $2 \mathrm{~b}$ provides the waveform obtained for the combined motion of loaded cell plus fiber. It is seen that this pattern reflects the simple summation of the two individual waveforms, with the amplitudes scaled according to Eq. (3). Fourier transformation (Fig. 2b, right) confirms this simple summation, showing a peak at the frequency of fiber motion $\left(f_{0}\right)$ and spectral components at and above the frequency $\left(f_{1}\right)$ of the sinusoidal voltage $V$. The latter reflects harmonics produced by the nonlinear Boltzmann process in the electromotile response. Significantly, there is no energy at the sum and difference frequencies $\left(f_{0} \pm f_{1}\right)$, where principal intermodulation components are expected.

With the assumption that the dependence of cell stiffness $K$ upon voltage can also be expressed as a Boltzmann function, $K$ can be represented as follows $\left(b_{0}, b_{1}\right.$, and $b_{2}$ are constants):

$$
K=\frac{b_{0}}{1+\exp \left(-b_{1} V+b_{2}\right)}
$$

In this case, the resultant waveform for the combined motion (Fig. 2c, left) clearly shows periodic amplitude variations in the $f_{0}$ response. This amplitude modulation is reflected in the spectrum by the peaks $f_{0}+f_{1}$ (Fig. 2c, right). An additional observation is that no significant second harmonic of the fiber frequency $\left(f_{0}\right)$ is predicted by the simple model.

It is conceivable that the cell's stiffness is not directly dependent on the membrane potential, but instead is more closely related to loaded cell-length change $(x)$. This case is once again simulated by a Boltzmann process $\left(c_{0}, c_{1}\right.$, and $c_{2}$ are constants):

$$
K=\frac{c_{0}}{1+\exp \left(-c_{1} x+c_{2}\right)}
$$

Since the denominator of the equation for $x$ (Eq. 3) also implicitly contains $x$, the displacement is the solution of a nonlinear equation. Not surprisingly, this nonlinear stiffness also produces amplitude modulation, as depicted in the waveform and spectra shown in Figure 2d. In this case, however, the second harmonic of $f_{0}$ is no longer negligible.

While both voltage and length dependence yield complex spectra, it is relatively easy to distinguish the 
two cases experimentally. If one of the driving signals stimulates electromotility while the other displaces the fiber, then the resultant intermodulation could be the result of either voltage or length dependence. However, if a complex (two-component) signal is used to displace the fiber and no electrical stimulus is delivered directly to the cell, then there can be no voltagedependent stiffness change and any nonlinearity will be a result of a putative length dependence of cell stiffness. Our experiments are designed to test these various possibilities. In a representation of the case when both sinusoidal signals $x_{0}$ and $x_{1}$ (with frequencies $f_{0}$ and $f_{1}$ ) drive the fiber, loaded-fiber displacement can be simulated as follows:

$$
x=\left(x_{0}+x_{1}\right) \frac{k_{0}}{K(x)+k_{0}}
$$

In the above, $K(x)$ is substituted from Eq. (6). As seen in Figure 2e, in this case both waveform and spectral configuration are different from the ones shown above, but the response will contain intermodulation between the two frequencies, a significant $2 f_{0}$ component, as well as a complete line spectrum involving combinations of multiples of $f_{0}$ and $f_{1}$. It is emphasized that if the cell stiffness $K$ were not dependent on cell length, but was either constant or voltage dependent, the spectrum would be similar to that seen in Figure $2 \mathrm{~b}$.

In the Methods section we considered the consequences of inadequate contact between the driven fiber and the cell. Here, this possibility is addressed theoretically. Inadequate contact yields rectification of the restoring force exerted by the cell upon the fiber. It is as if the stiffness load on the fiber was asymmetrical, present for some fraction of the half-cycle during cell compression and absent otherwise. The simulation is taken for the case of contact during the entire halfcycle. This can be taken into account by setting $K=$ 0 for the half-cycles when the fiber moves away from the cell or the cell moves away from the fiber. Inasmuch as this maneuver is equivalent to modulating the cell's stiffness, a nonlinear response is expected. One notes that the same decoupling, hence nonlinearity, is expected if the signals are conveyed to the bimorph, even if the cell constitutes a passive load. The results of such a simulation are shown in Figure 2f. The left plot of Figure 2f provides the waveform, while the right plot gives the Fourier spectrum. It is apparent that one sees waveform distortion and a very rich spectrum, including intermodulation components. Because of this similarity, it is essential to be vigilant in assuring that positive results do not arise due to simple coupling-decoupling of cell and fiber. As in the case of the driven-fiber response with the assumption of nonlinear length-dependent stiffness (Fig. 2e), here too there is a complex spectral profile between $f_{0}$ and $2 f_{0}$.
The above modeling effort is not meant to provide an accurate representation of the experimentally obtained data. Instead, it is a simplified theoretical framework to guide the reader among the various possibilities that need to be considered in this work.

\section{Experimental results}

Modulation of axial stiffness. We examined 46 outer hair cells using low-frequency sinusoidal voltages $(1-10 \mathrm{~Hz})$ to elicit electromotility. Among these, there was a clear indication of amplitude modulation in 38 cells. Two examples are presented in Figure 3 to demonstrate the effect. The top panels show in the background the fiber motion (at $100 \mathrm{~Hz}$ ) when not loaded by the cell; they also depict the loaded-fiber motion in the foreground. The first second of the latter plots represents loaded conditions without electromotile response being elicited. In both cases the loaded-fiber motion is smaller than the unloaded one. In the second 1-s interval, the combined cell and fiber motion is demonstrated when electromotility is activated at 10 Hz. In the center panels of Figure 3, the response is shown high-pass filtered in order to remove lowfrequency motility response and expose amplitude changes in the high-frequency signal, i.e., in the loaded-fiber motion. In the same plots, the low-passfiltered responses are also included to represent the cell's loaded motility. The examples are chosen to represent different degrees of nonlinearity seen in the loaded electromotile responses. Thus, the electromotile response of cell 42 contains some second harmonic and DC. The response of cell 46 is highly distorted with several harmonics evident. The modulation of the high-frequency signal by the lowfrequency one is quite clear in the center plots having an expanded time axis. Response decreases when the excluded cell segment expands (plotted up) and increases upon contraction (plotted down). In the bottom panels of Figure 3, the spectra of the loadedfiber motion during the first 1-s interval and during electromotile response (obtained from the second 1-s span) are shown. When no motility is evoked, the only significant spectral component is at $100 \mathrm{~Hz}$. The spectra obtained during motility contain, aside from the expected motile response spectrum $(10 \mathrm{~Hz}, 20 \mathrm{~Hz}$, etc.), the prominent difference and sum components at 90 and $110 \mathrm{~Hz}$, representing intermodulation. Interestingly, when the electromotile response itself contains significant harmonics, as for cell 46, they too intermodulate with the $100-\mathrm{Hz}$ fiber motion. This is seen in the spectral lines at frequencies $100 \pm n 10$. No significant second harmonic component of the fiber motion appears in either spectrum.

Voltage or length dependence? In Figure 4 two examples of the results from a different experiment are 
FIG. 3. Two examples of experimental results. (a and d) Free-fiber motion in response to $100-\mathrm{Hz}$ sinusoidal drive (thin dotted lines) and loaded-fiber response during stimulation of electromotility during the second half of the signal (heavy line). Comparison of the first 1-s period of loaded- and free-fiber motions provides an indication of contact between fiber and cell and affords the computation of $\zeta$ (see text). (b and e) High-pass filtered version of loaded-fiber motion during elicitation of motile response (thin dotted line), in comparison with the lowpass filtered (solid line) version of the same response. Only a segment of the response is shown on an expanded time scale. The high-pass response clearly shows the amplitude modulation of fiber motion, while the low-pass response is the loaded electromotility. (c and f) Fourier spectra of loaded-fiber motion computed from the first (squares, no lines) and second 1-s intervals (heavy lines) of the loaded-fiber response ( $\mathbf{a}$ and $\mathbf{d}$ ). Note intermodulation components at 90 and $110 \mathrm{~Hz}$. In this and all other figures, cell contraction is plotted down, elongation is plotted up. Cell lengths: 70 and 60 $\mu \mathrm{m}$; both were $75 \%$ excluded.
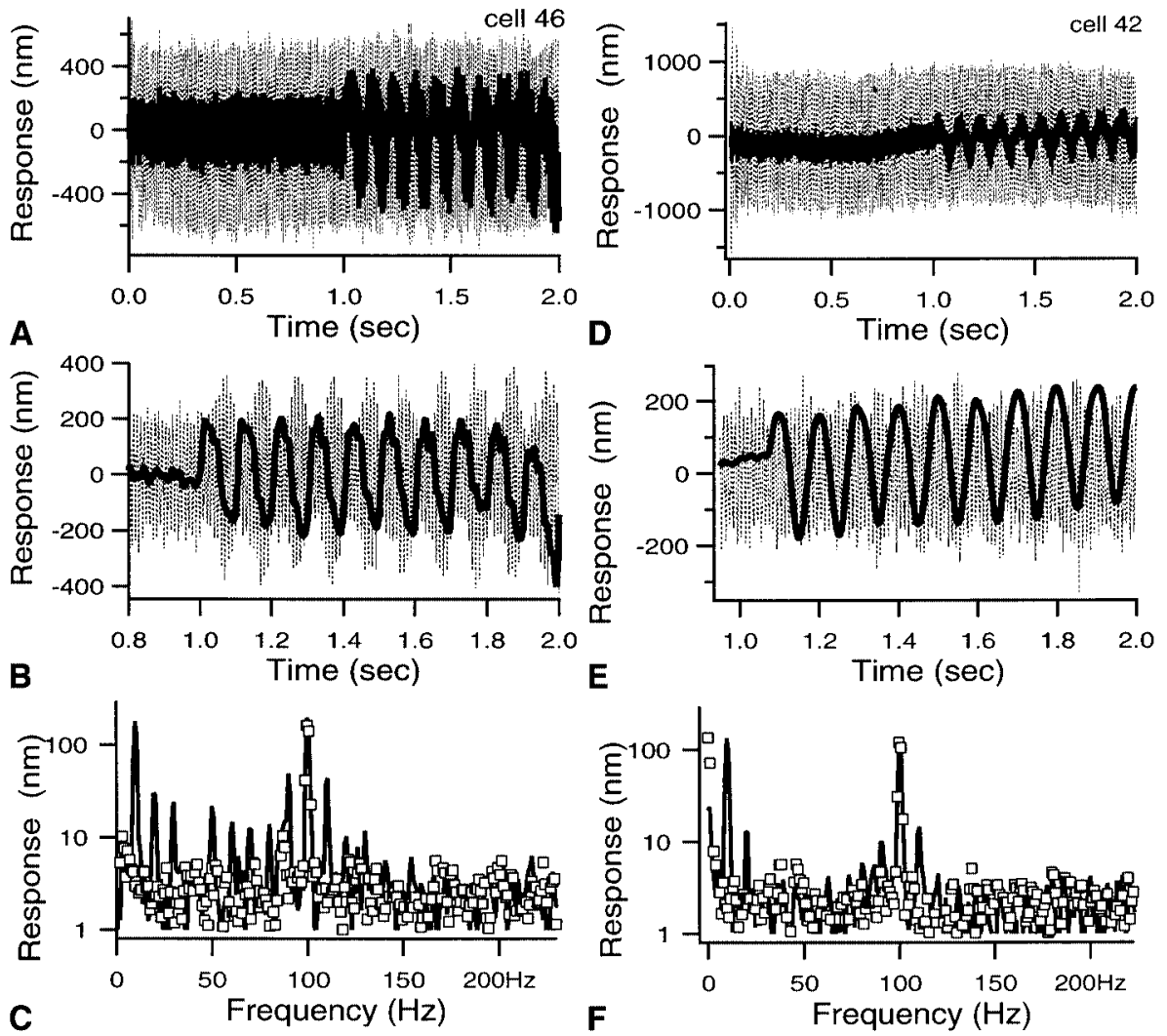

enumerated. Here both high- and low-frequency signals $(100 \mathrm{~Hz}$ plus $10 \mathrm{~Hz}$ ) are applied to the bimorph that drives the fiber. The cell functions as a load of possibly length-dependent stiffness, but its electromotile response is not elicited. The top traces show the waveforms of loaded-fiber motion, while the bottom panels give the spectra of the first and second 1-second segments of the loaded response. During the first half, one sees the $100-\mathrm{Hz}$ component, whereas during the second half, the $10-$ and $100-\mathrm{Hz}$ components are present. Any spectral component that emerges from the noise level does not have the correct frequency, i.e., $100 \pm 10 \mathrm{~Hz}$. Furthermore, there is no detectable second harmonic $(200 \mathrm{~Hz})$ of the fiber frequency, or any meaningful spectral structure between 100 and $200 \mathrm{~Hz}$. It is concluded that in these examples, there is no measurable length-dependent stiffness. Experiments in which both low- and high-frequency signals were conveyed to the bimorph were carried out on 16 cells. Small intermodulation components were present in six experiments; all six also had intermodulation when the low-frequency voltage was presented to the cell. In seven experiments there was no length-dependent stiffness, but voltage-dependent stiffness was evident. Finally, in three experiments neither length- nor voltage-dependent stiffness was detected. We have performed several experiments where stiffness measurements were made while different degrees of constant pressure were exerted on the cell by the fiber. The resulting data tend to be complex (some are shown in Appendix 1).

Input-output functions. The above experiments established the existence of a voltage-dependent stiffness in outer hair cells. In the following, some properties of this stiffness are examined. Our first concern is to determine the functional dependence of stiffness upon driving voltage. To this end, the command voltage to the microchamber was a sequence of positive/ negative steps, increasing in size from $\pm 40 \mathrm{mV}$ to \pm 280 $\mathrm{mV}$. The duration of each step was $40 \mathrm{~ms}$. The glass fiber was driven at $100 \mathrm{~Hz}$ and its stiffness $\left(k_{0}\right)$ was known. Consequently, it was possible to determine the absolute stiffness of the cell at any value of the command voltage from the unloaded $\left(x_{0}\right)$ and loaded $(x)$ amplitudes of the $100-\mathrm{Hz}$ fiber motion:

$$
K=k_{0}\left(\frac{x_{0}}{x}-1\right)
$$

In Figure 5 an example is provided. In the top panel both free-fiber motion and loaded-fiber motion are shown in the background and foreground, respectively. During loaded-fiber motion the command voltage is applied to the microchamber. The center panel shows the high-pass-filtered version of the loaded-fiber motion. The trace clearly demonstrates the expected 


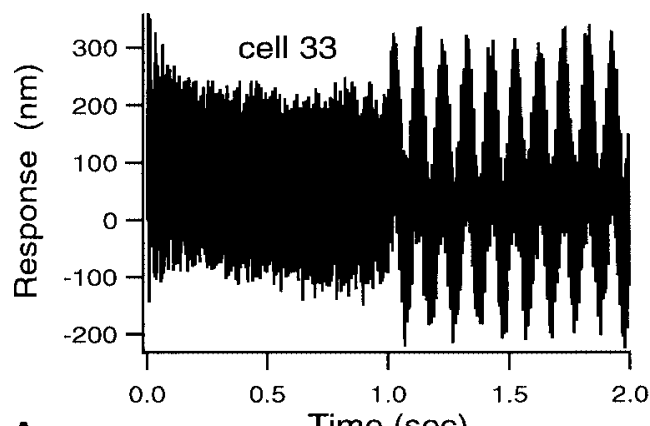

A
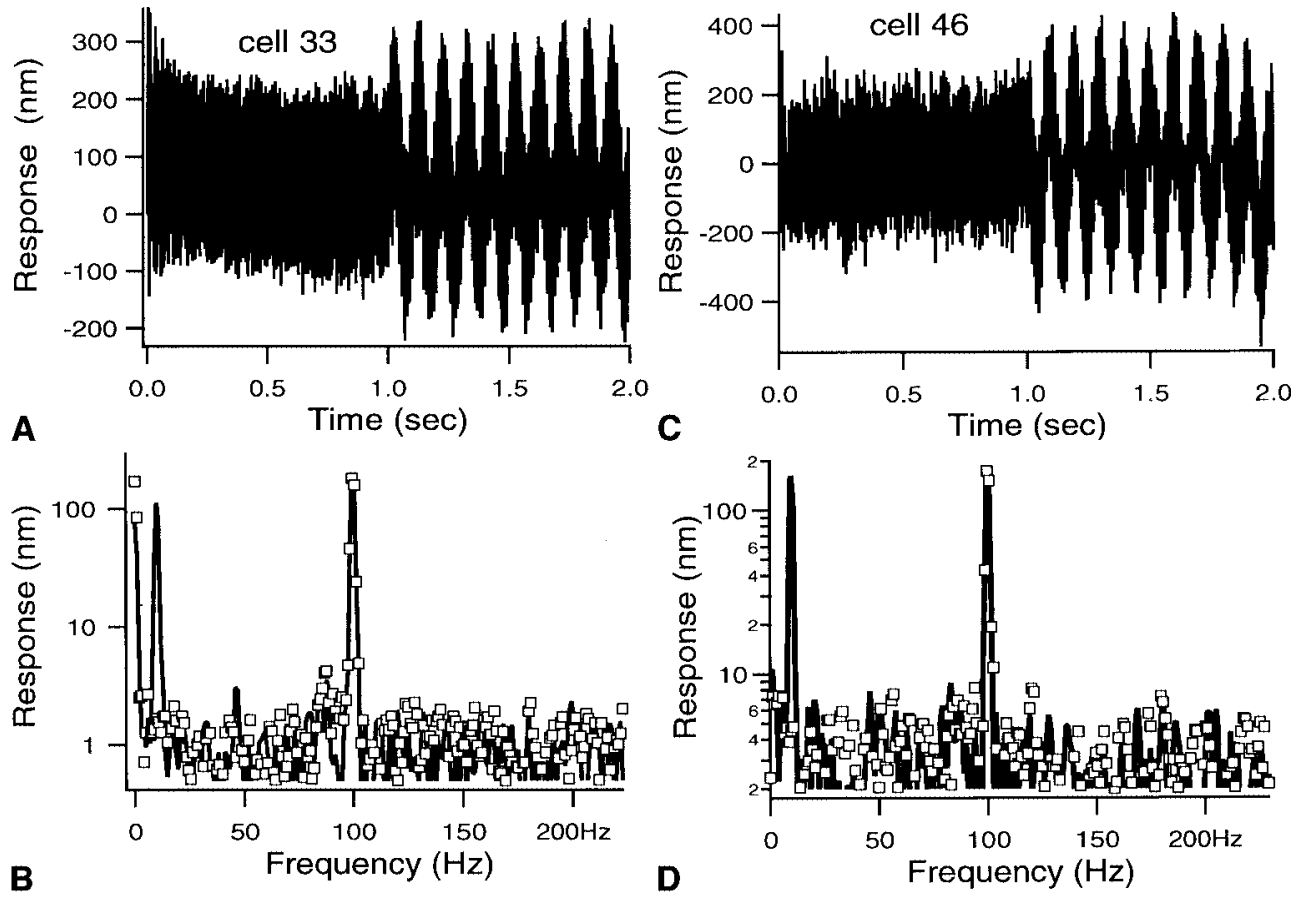

FIG. 4. Two examples of experimental results. (a and c) Loaded, driven fiber motion when both 100- and 10-Hz signals are combined to drive the fiber and no voltage is presented to the cell. (b and d) Fourier spectra obtained from the first (squares, no lines) and second 1-s interval (heavy lines) of $\mathbf{a}$ and $\mathbf{c}$. There is no detectable modulation or second harmonic in the spectra. Cell length: $45 \mu \mathrm{m}, 70 \%$ excluded.

amplitude modulation by the DC pulses. From the modulated fiber motion the cell's stiffness may be calculated using Eq. (8) at each command voltage. The result is plotted in the lower panel of figures with open circles. The plot is asymmetrical and it saturates for both negative and positive voltages. The asymmetry is such that decrease in stiffness is more extensive than its increase. The plot is fitted with a second-order Boltzmann function, using the Levenberg-Marquardt algorithm built into the Igor Pro (WaveMetrics, Inc.) analysis program. The result of the fit is shown with the continuous line. It is apparent that the voltage dependence of somatic stiffness is nonlinear and that the Boltzmann process provides a reasonable description of the functional form of this dependence. The above paradigm was performed on 22 cells with results similar to the demonstration in Figure 5.

Stiffness change vs. electromotility. Just as the modulated fiber motion may be derived by high-pass filtering the loaded fiber response, low-pass filtering reveals the loaded electromotile response of the cell. An example of this is shown in the middle trace of Figure 6. In order to show amplitude modulation of the fiber's displacement, the high-pass filtered response is given in the upper panel. The lower panel provides a plot of this motile response as a function of command voltage. As expected from past work (Evans et al. 1991), the function is nonlinear, having a characteristic saturating asymmetry that favors contractions over elongations. The derived stiffness is also plotted along with the motile response. Both plots are reasonably well fitted with the same Boltzmann function. It is evident that stiffness and motility covary as command voltage changes.

Frequency response of stiffness change and motility. A variety of experiments were conducted with higher probe-frequencies and a corresponding range of higher modulation frequencies presented to the microchamber. The two commonly used higher probe frequencies were 1000 and $2000 \mathrm{~Hz}$. With the former, voltage bursts at 10 (or 20), 50,100, and $200 \mathrm{~Hz}$, while with the latter, at 20,50,100,200, and $500 \mathrm{~Hz}$ were used. Thirty-five cells were examined with these paradigms. In another experimental series, the fiber was moving at $2000 \mathrm{~Hz}$ and the electrical signals were at 50, 500, 1000, 1500 and $1750 \mathrm{~Hz}$. In this series 22 cells were studied. An example from the latter series is provided in Figure 7.

As the voltage-dependent stiffness of the cell alters the load on the driven fiber, amplitude modulation ensues, as we have seen above. The actual stiffness change can be derived from the magnitudes of the side-band components in the spectrum, $f_{0} \pm f_{m}$. In simple sinusoidal amplitude modulation, the magnitude of either side band signal is $A m / 2$, where $A$ is the amplitude of the carrier and $m$ is the modulation index. Consequently, the amplitude of the modulating signal is twice the side band. Having derived the spectral magnitudes for the carrier $\left(B_{\mathrm{car}}\right)$ and the side band 


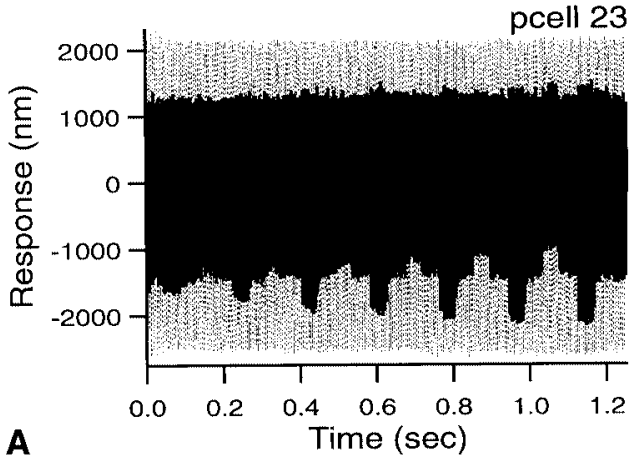

A
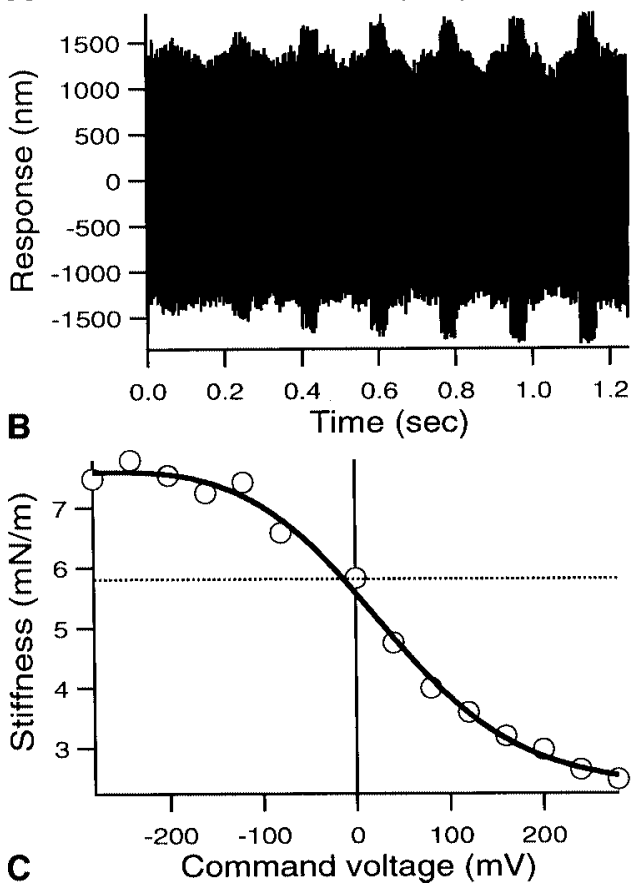

FIG. 5. Example of response when electromotility is elicited by a series of DC pulses increasing in magnitude from \pm 40 to $\pm 280 \mathrm{mV}$. Fiber motion at $100 \mathrm{~Hz}$. (a) Free-fiber motion is shown by a dotted line, loaded-fiber motion is superimposed with a heavy line. (b) Highpass filtered fiber motion shows amplitude modulation. (c) Computed cell stiffness (open circles) at different command voltages. Stiffness is obtained from the amplitudes of free- and loaded-fiber motions using eq. 8. Data points are fitted with a second-order Boltzmann function (heavy line) of the form: $K=k_{1} /\left\{1+\exp \left(-k_{2} V+k_{3}\right)[1+\right.$ $\left.\left.\exp \left(-k_{4} V+k_{5}\right)\right]\right\}+k_{6}$ Parameters: $k_{1}=104, k_{2}=0.004, k_{3}=2.79$, $k_{4}=-0.013, k_{5}=-0.088, k_{6}=2.33$. When the command voltage is negative (as applied to the microchamber), the excluded cell segment is hyperpolarized and expands. Increased stiffness corresponds to hyperpolarization and cell expansion. Cell length: $60 \mu \mathrm{m}, 75 \%$ excluded.

$\left(B_{\mathrm{sb}}\right)$ at any modulation frequency, the amplitude of stiffness change $(\Delta K)$ can be calculated:

$$
\begin{aligned}
\Delta K=k_{0}\left(\frac{x_{0}}{B_{\mathrm{car}}-2 B_{\mathrm{sb}}}-1\right)- & k_{0}\left(\frac{x_{0}}{B_{\mathrm{car}}+2 B_{\mathrm{sb}}}-1\right) \\
& =k_{0} x_{0}\left(\frac{4 B_{\mathrm{sb}}}{B_{\mathrm{car}}^{2}-4 B_{\mathrm{sb}}^{2}}\right)
\end{aligned}
$$
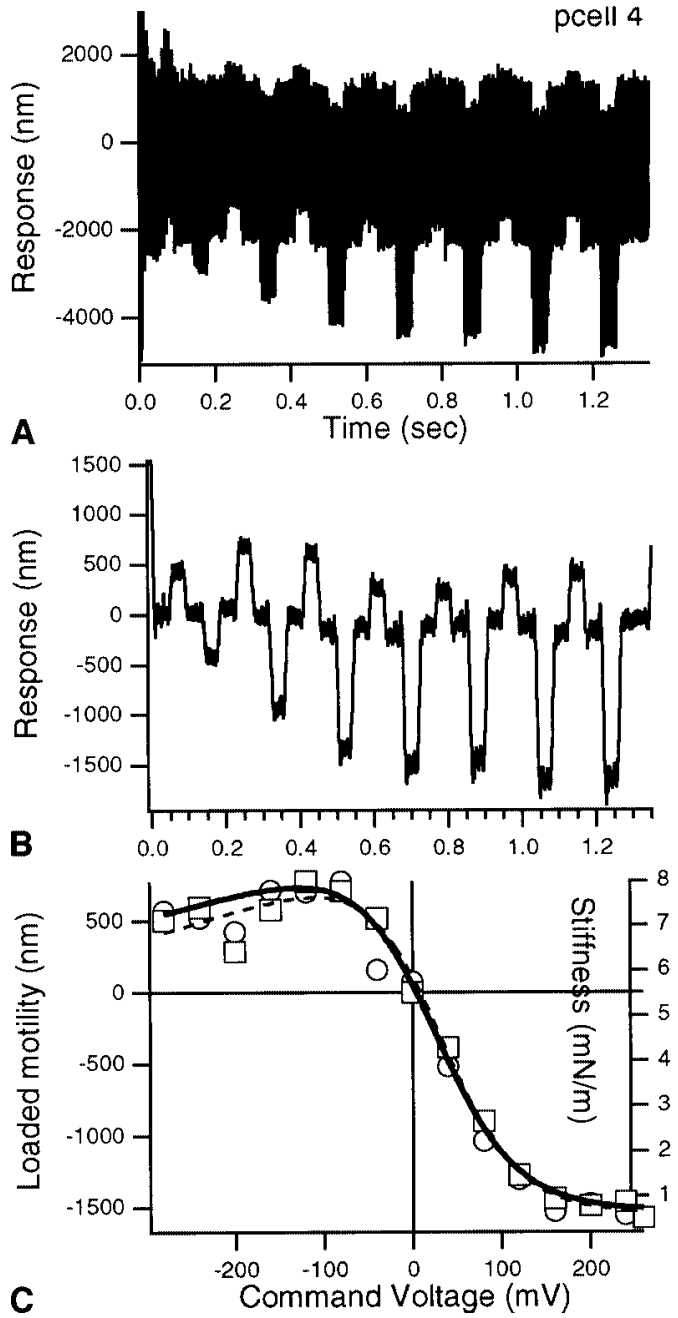

FIG. 6. Another example as in Figure 5. (a) High-pass-filtered loaded-fiber motion showing amplitude modulation. (b) Low-passfiltered loaded-fiber motion provides loaded electromotile response. (c) Cell stiffness (open circles) derived from the amplitudes of unloaded- and loaded-fiber displacement at different command voltages (using eq. 7). Loaded motile responses (open squares) measured from b are also given. Second-order Boltzmann fits are also shown (solid line: stiffness, parameters of fit: $k_{1}=73.7, k_{2}=-0.02, k_{3}=1.76$, $k_{4}=0.022, k_{5}=0.32, k_{6}=1.78$; dashed line: motility, parameters of fit: $k_{1}=11351, k_{2}=-0.022, k_{3}=0.87, k_{4}=0.024, k_{5}=0.38$, $k_{6}=-1541$. Cell length: $55 \mu \mathrm{m}, 80 \%$ excluded.

where, as before, $k_{0}$ is the fiber's stiffness and $x_{0}$ is the free fiber motion amplitude.

Figure $7 \mathrm{a}$ gives an example of free-fiber motion in the background and loaded-fiber motion, while electromotile response (elicited at five different frequencies) is plotted in the foreground. From the amplitudes of free-fiber motion and loaded-fiber motion during zero voltage to the microchamber, one computes that this cell's resting stiffness is $12.2 \mathrm{mN} / \mathrm{m}$. The five responses are separately Fourier transformed and Figure $7 \mathrm{~b}$ gives, as an example, the resulting spectrum when the electrical frequency was $500 \mathrm{~Hz}$. From the spectrum three numbers can be derived. These are 

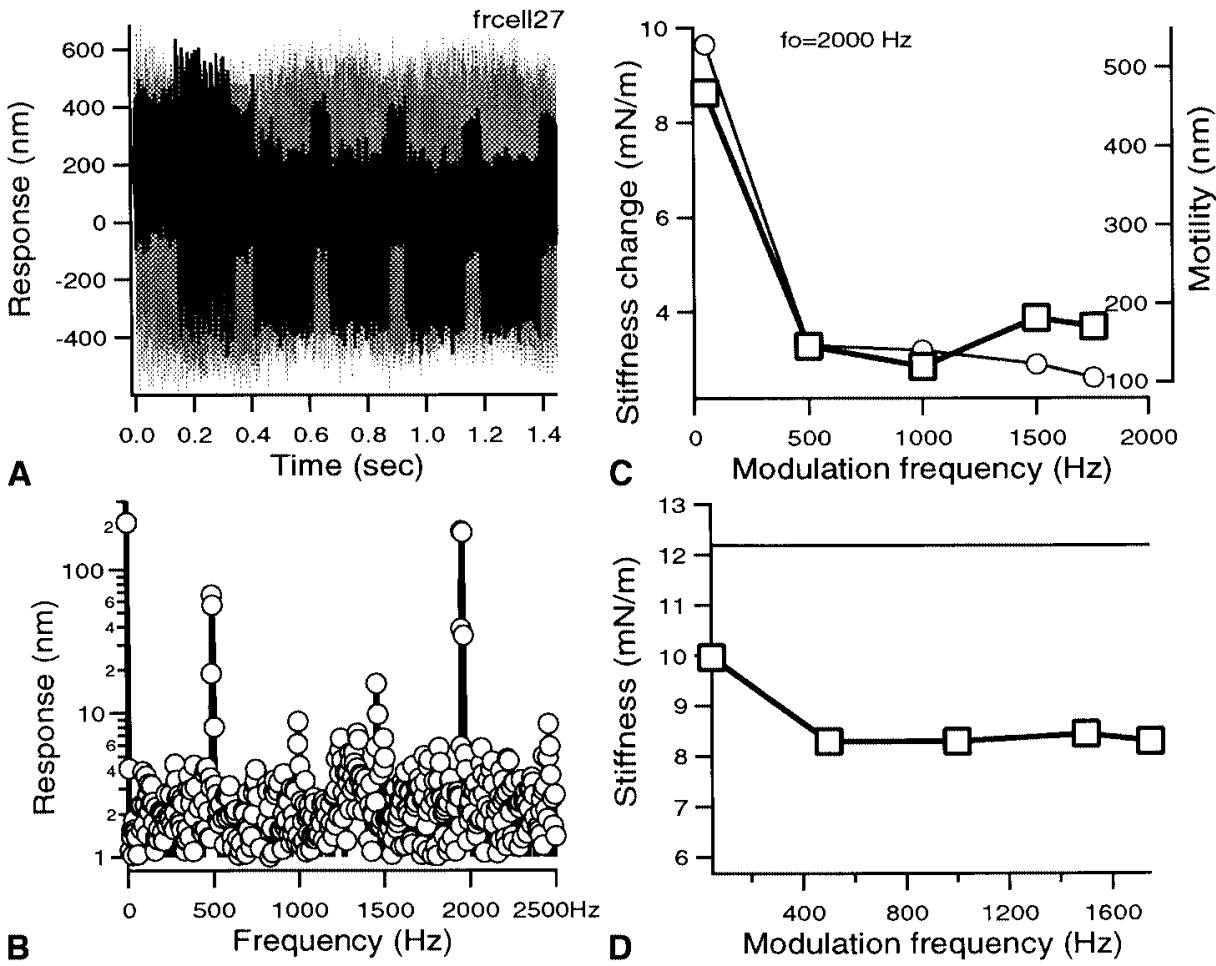

FIG. 7. Example of obtaining the frequency dependence of stiffness. (a) Free-fiber motion is shown with dotted lines in the background and loaded-fiber motion is superimposed with heavy lines. Fiber motion frequency: $2000 \mathrm{~Hz}$. Motility is elicited by sinusoidal command voltages at 50, 500,1000,1500, and $1750 \mathrm{~Hz}$ in the successive bursts. (b) Example of spectrum when the command voltage to the cell is at $500 \mathrm{~Hz}$. Note spectral components at the fiber frequency $(2000 \mathrm{~Hz})$, at the command voltage frequency $(500 \mathrm{~Hz})$, and at the

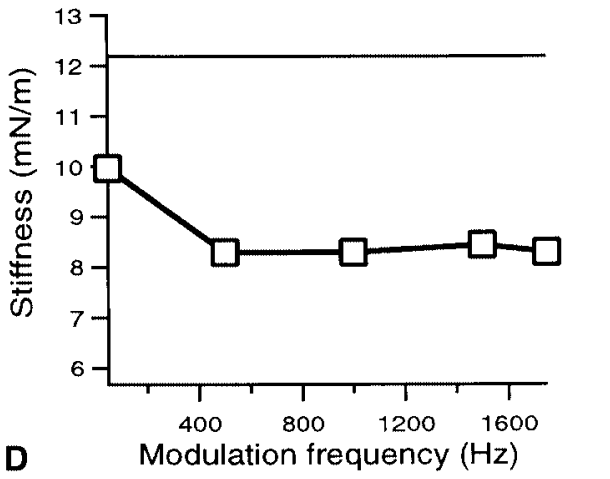

lower and upper side-band frequencies $(1500$ and $2500 \mathrm{~Hz})$. (c) AC stiffness change (squares, heavy lines) calculated from the spectral components using eq. 9 at the different modulation frequencies. The amplitude of loaded motile response is superimposed (circles, thin lines). (d) DC stiffness change at the different modulation frequencies. Cell's resting stiffness is indicated with the thin horizontal line. Cell length: $55 \mu \mathrm{m}, 75 \%$ excluded.

the amplitude of the carrier $\left(B_{\mathrm{car}}\right)$ at $2000 \mathrm{~Hz}$, the amplitude of the lower side band $\left(B_{\mathrm{sb}}\right)$ at $f_{0}-f_{m}$, and the amplitude of the motile response at $f_{m}$. With the aid of Eq. (9) the stiffness change is computed and plotted in Figure 7c. Appended to this panel is the peak-to-peak amplitude of the loaded motile response. This example serves to represent frequency responses from the population of cells in this experiment. Simply stated, loaded motility and stiffness-change co-vary as electrical frequency changes.

It is apparent from Figure $7 \mathrm{a}$ that the motile response contains a significant DC component in the depolarizing direction. This DC response is relatively small at $50 \mathrm{~Hz}$ and becomes larger and approximately constant at higher frequencies. We have reported on this finding in the past (Dallos et al. 1993b; He et al. 1994). Due to the DC response component, during the presentation of voltage bursts, we have not only the cycle-by-cycle stiffness change that is quantified in Figure $7 \mathrm{c}$, but the baseline stiffness of the cell also changes. This stiffness, obtained from the amplitudes of a high-pass filtered version of the loaded-fiber motion (not shown), is plotted in Figure 7d. During the first burst $(50 \mathrm{~Hz})$, the modest DC response

reduces the baseline stiffness of the cell from 12.2 to $10 \mathrm{mN} / \mathrm{m}$. During the other bursts the stiffness decreases to approximately $8.3 \mathrm{mN} / \mathrm{m}$. The AC stiffness changes of Figure $7 \mathrm{c}$ are superimposed on these values.

Another means whereby correlation between stiffness change and motile response may be sought is to relate pairs of values, obtained from different cells and at different electrical frequencies delivered to the cells. In Figure 8, the top panel gives an example of a spectrum from an experiment where the fiber was vibrated at $\sim 2000 \mathrm{~Hz}$ and electromotility was evoked at $200 \mathrm{~Hz}$. The now familiar spectral peaks at $200 \mathrm{~Hz}, 400 \mathrm{~Hz}$, etc., as well as intermodulation components at $\sim 1800$ and $\sim 2200 \mathrm{~Hz}$ are clearly seen. The two marked components, the loaded electromotile response and the lower side band, are plotted in the bottom panel for the varying modulation frequencies and across cells. It is apparent that there is a positive correlation between motile response magnitude and the magnitude of the side band.

Isometric force When the motile outer hair cell is loaded by a constant stiffness, $k_{0}$, it delivers a force, $F$ to the load. If the load approaches infinity, the force 


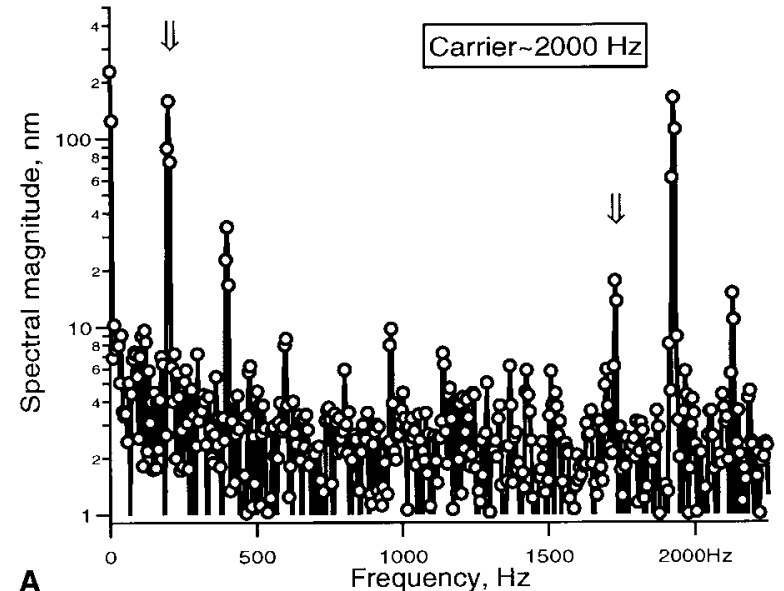

A

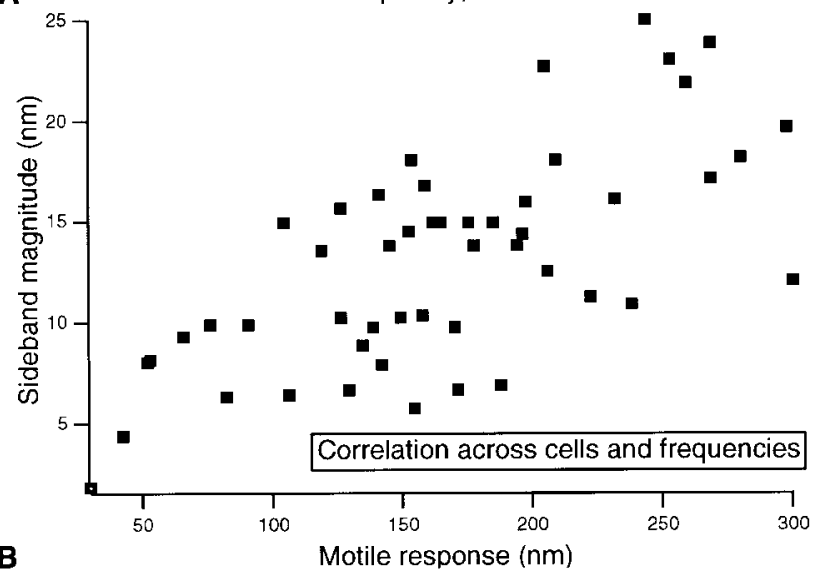

FIG. 8. (a) Another example of Fourier spectrum obtained under the experimental conditions of Figure 7. Here the fiber frequency is $2000 \mathrm{~Hz}$, the command voltage is $200 \mathrm{~Hz}$. The two arrows point to the two variables, spectral component magnitudes at the modulation frequency and lower side-band frequency, that are plotted against one another in $\mathbf{b}$. The pairs of data are obtained across all modulation frequencies and cells in the data collection using the paradigm stated above.

tends toward its asymptotic value, the isometric, or stall force, $F_{\infty}$ :

$$
F=G(V) \frac{k_{0} K(V)}{k_{0}+K(V)} ; \quad F_{\infty}=G(V) K(V)
$$

where $G(V)$ is the unloaded electromotile response of the cell. It is of interest to examine this isometric force, inasmuch as it probably best represents the force delivered by outer hair cells in situ, where their lengths are somewhat fixed by the organ of Corti matrix. In Figure 9 an example is shown of the voltage dependence of this isometric force. The example is chosen because the cell's resting stiffness $(5.9 \mathrm{mN} / \mathrm{m})$ is close to the average quiescent stiffness of our cells. In the top panel the cell's stiffness and its no-load motile response are shown as data points, along with best-fit Boltzmann functions. The product of these functions, the isometric force, is plotted in the bottom panel of Figure 9 with the heavy line. For comparison, the isometric

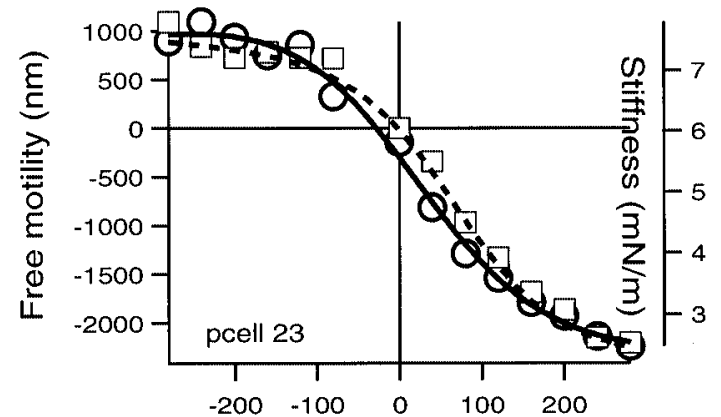

A Command voltage $(\mathrm{mV})$

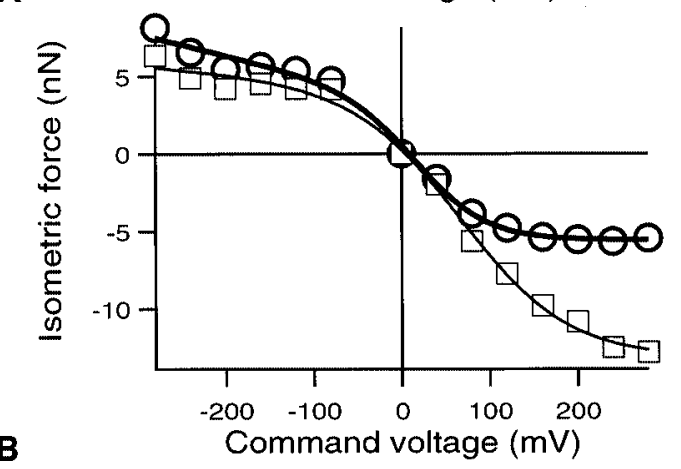

FIG. 9. Examples of input-output functions that are used to compute isometric force. (a) Stiffness (circles) and free motility (squares) as functions of command voltage. Experimental paradigm as in Figure 5. Both sets of data are fitted with second-order Boltzmann functions (stiffness: heavy line, fit parameters: $k_{1}=104, k_{2}=0.004, k_{3}=2.79$, $k_{4}=-0.013, k_{5}=-0.088, k_{6}=2.33 ;$ motility: dotted line, $k_{1}=$ $6084, k_{2}=-0.0005, k_{3}=0.0083, k_{4}=-0.016, k_{5}=-0.48, k_{6}=$ -2266). (b) Isometric force computed under two different assumptions: (1) force equals variable stiffness of the cell times free motility (circles, heavy line; Boltzman fit parameters: $k_{1}=826, k_{2}=-0.001$, $\left.k_{3}=4.4, k_{4}=-0.025, k_{5}=-0.56, k_{6}=-5.6\right) ;(2)$ force equals constant resting stiffness of the cell times free motility (squares, thin line; fit parameters: $k_{1}=1111, k_{2}=-0.0002, k_{3}=4.1, k_{4}=-0.016$, $\left.k_{5}=-1.16, k_{6}=-13.2\right)$. Cell length: $60 \mu \mathrm{m}, 75 \%$ excluded.

force that would exist if the cell's stiffness were not voltage dependent, is shown with the thin line. The effect of voltage-dependent stiffness on force production is opposite during depolarizing and hyperpolarizing epochs. During hyperpolarization, when the cell expands and pushes against the load, the force increases beyond that seen with constant stiffness. However, during depolarization and its associated cell contraction, when the cell pulls away from the load, the force is diminished. Twenty-three cells were examined as in Figure 9; the largest isometric force recorded is approximately $30 \mathrm{nN}$. From the low-voltage slope of fitted second-order Boltzmann functions to the isometric force plots, one can estimate the force-per-driving voltage values. Taking the average value of $0.115 \mathrm{mV} /$ $\mathrm{mV}$ (from Appendix 2) transformation between membrane potential and command voltage, a value of 0.54 $\mathrm{nN} / \mathrm{mV}$ is obtained for the example shown. From curve-fits to all stiffness and force plots, the average 

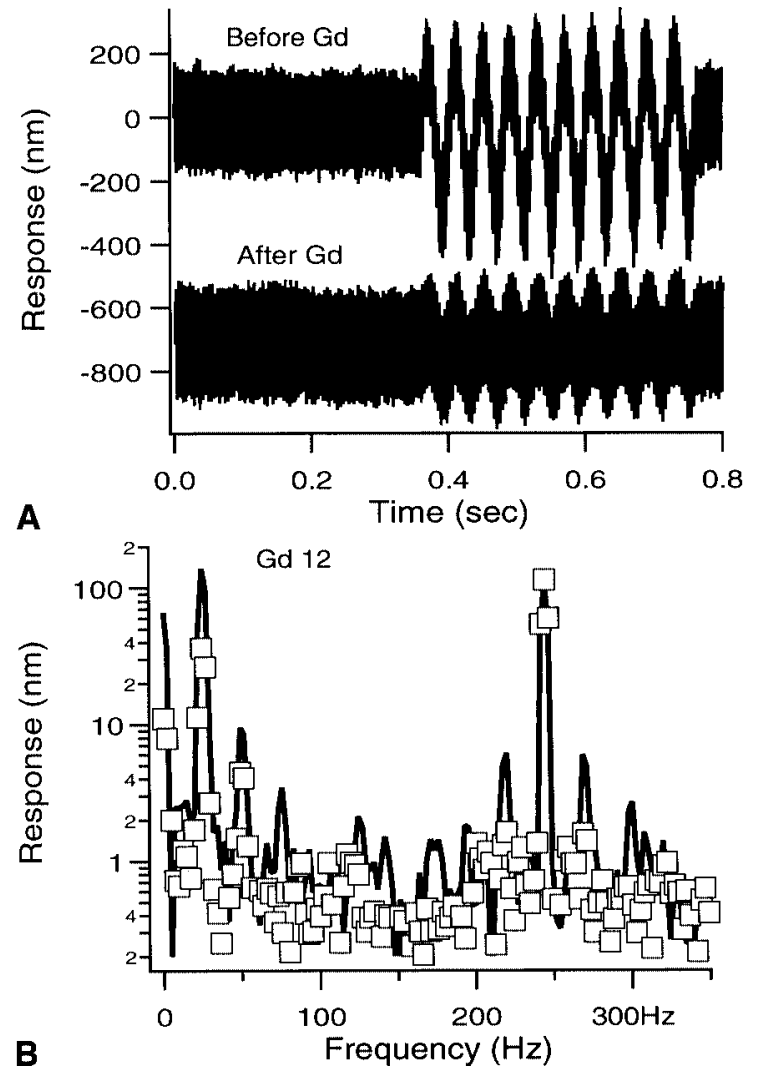

FIG. 10. Demonstration of the effect of gadolinium on cell stiffness and motility. (a) Loaded motility before (top) and after (bottom) application of gadolinium to the bath. Fiber motion at $250 \mathrm{~Hz}$, command voltage at $20 \mathrm{~Hz}$. Motility is elicited only during the second half of the presentation period. (b) Spectra computed during the elicitation of motility. Control condition (heavy lines) and with gadolinium (squares). Cell length: $65 \mu \mathrm{m}$ 75\% excluded.

value of $0.856 \mathrm{nN} / \mathrm{mV}$, with a range of $0.365-1.54 \mathrm{nN} /$ $\mathrm{mV}$, obtains for isometric force. These slopes are larger but of the same order of magnitude as that obtained by Iwasa and Adachi (1997), who computed a value of $0.1 \mathrm{nN} / \mathrm{mV}$. From the same group of input-output functions, the low-voltage stiffness slopes are also available. The average is $0.286 \mathrm{mN} / \mathrm{m} / \mathrm{mV}$, with a range of $0.055-0.782 \mathrm{mN} / \mathrm{m} / \mathrm{mV}$.

The effect of gadolinium. It is known (Santos-Sacchi 1991; Kakehata and Santos-Sacchi 1996) that lanthanides, e.g., gadolinium, have a deleterious effect on electromotility. While this response is not fully eliminated when gadolinium is applied to the exterior of the cell, it is significantly diminished. We examined the effect of application of gadolinium $(1 \mathrm{mM})$ to the bath. Both motility and stiffness were obtained with the two-frequency paradigm used in Figure 3. An example of the results is presented in Figure 10. The top trace depicts loaded fiber motion at $100 \mathrm{~Hz}$ without (first half) and with (second half) electromotility elicited at $10 \mathrm{~Hz}$. This first trace represents the control condition. The second trace shows the response after
$\mathrm{Gd}^{3+}$ was applied. The loaded-fiber response during the first half of the time period is essentially unchanged. During the second half, one observes a large reduction in the low-frequency electromotile response. A quantitative evaluation can be obtained by comparing Fourier spectra of the second halves of the before and after $\mathrm{Gd}^{3+}$ responses. This is done in the lower panel. The response at the carrier frequency $(100 \mathrm{~Hz})$ is not altered. However, the loaded motile response at $10 \mathrm{~Hz}$ is reduced by some $12 \mathrm{~dB}$ and its harmonic content is also diminished. Interestingly, the intermodulation at $100 \pm 10$ and $100 \pm 20 \mathrm{~Hz}$ is greatly diminished. These findings were duplicated in 17 cells. It is concluded that gadolinium has a strong deleterious effect on voltage-dependent stiffness, not unlike its influence on electromotility.

\section{DISCUSSION}

By measuring the amplitude of driven vibrations of a fiber that was brought against an isolated outer hair cell while the cell was electrically stimulated in a microchamber (Evans et al. 1989, 1991), it was shown that the amplitude of fiber motion was significantly modulated during the contraction-elongation cycle (electromotility) of the cell. The finding is interpreted as a voltage-dependent axial stiffness change of cochlear outer hair cells. The cell presents a pure reactive stiffness load to the fiber, the mechanical impedance of which is also a pure stiffness at the frequencies used in this work (see Methods). If the amplitude of the fiber motion changes, this must be the consequence of an altered load upon it, in other words, altered cell stiffness. There are different causes of the changing load (stiffness). One possibility, favored here, is that the stiffness is voltage dependent. Another is that cell stiffness depends on cell length. Finally, it is possible that the axial stiffness is nonlinear and depends on the state of compression of the cell. We construe the first two of these possibilities as representing active control over cell properties, only differing in the controlling variable. In contrast, the third is envisioned as a passive reflection of the possibly peculiar properties of the complex outer hair cell wall (Tolomeo et al. 1996; Oghalai et al. 1998; Spector et al. 1998), which might yield an asymmetry in stiffness for positive and negative axial force. Poor contact between cell and fiber is formally just an extreme case of such asymmetry, even though it arises from a different cause. It was argued that one could discriminate among these mechanisms by observing certain experimental outcomes. First, the existence of simple connectdisconnect behavior of cell and fiber during the stimulus cycle can be rejected by measuring the second harmonic content of fiber displacement. As long as 
the relative magnitude of the second harmonic does not increase from unloaded to loaded condition, one can be assured that contact is maintained throughout the fiber motion cycle. The mere existence of secure contact, however, which rules out the artifact of connect-disconnect, does not address inherently nonlinear cell stiffness. That contingency needs to be tested directly. The method devised for this, which at the same time tests for the length dependence of cell stiffness, is to use the cell as a passive load upon the driven fiber and ask if the load can be represented as a simple linear spring. The test is to drive the fiber with a twofrequency harmonic complex and examine the spectrum of cell displacement for intermodulation between the two frequencies. An even simpler means is to look for harmonics in the frequency spectrum of loaded-fiber motion. Direct tests with the two-frequency paradigm indicated a small effect, seen in a few cells. Thus, it cannot be ruled out that outer hair cell axial stiffness is mildly dependent on the cell's length or upon the instantaneous deformation of its envelope. This conclusion agrees with results obtained by inducing stiffness changes by various means (Hallworth 1997). The reciprocity of the motile mechanism (Weiss 1982; Iwasa 1993; Mountain and Hubbard 1994; Gale and Ashmore 1995; Kakehata and Santos-Sacchi 1995; Zao and Santos-Sacchi 1999) is noted, and the consequent indirect dependence of cell stiffness upon length is considered a given. It is to be emphasized, however, that these length-dependent effects (when detected) are significantly exceeded by the voltagedependent stiffness changes that constitute the main finding of this work. It is, in fact, surprising how small and ephemeral is the direct length dependence that emerges from these experiments. It is conceivable that if larger fiber displacements had been used, a more pronounced length dependence could have been demonstrated. To summarize, if a two-frequency signal is used to drive the fiber, intermodulation, if seen at all, is small (Fig. 4). In contrast, if one of the signals elicits electromotility while the other drives the fiber, intermodulation is prominent (Fig. 3). Thus, nonlinear axial cell stiffness is principally dependent on membrane potential and only secondarily on cell length. We note the caveat that none of the methods used in these experiments is capable of discriminating between direct voltage dependence and motility dependence. To explain, if somehow stiffness depended on the motile response itself and thus only indirectly on voltage, one could not separate this case from direct voltage dependence. Of course, it is more likely that motility itself depends on stiffness change (Dallos and He 2000).

The inherent nonlinearity of the axial cell stiffness is automatically assessed when the spectrum of loadedfiber motion is calculated. An asymmetric nonlinearity would result in a larger second harmonic in loaded than in the unloaded condition. Our data indicate that such asymmetry is not significant (Fig. 3 and Fig. 4 ) in most cases, and thus the passive cell obeys Hooke's law.

A related experimental series in which the cell's membrane potential was controlled with the wholecell voltage-clamp technique (Hamill et al. 1981) was also published recently (He and Dallos 1999). The conclusions from that more limited work were the same as those reached here. The patch-clamp experiments were used to establish the existence of the phenomenon. It was demonstrated that loaded-fiber response decreased during hyperpolarization (cell elongation) and increased during depolarization (cell contraction). The resting stiffness of the cell is probably reduced during deflation by the patch pipette, and the functional relationship between stiffness change and membrane potential is likely to be altered. Furthermore, it is difficult to maintain good seal while the cell is mechanically manipulated and it is also difficult to keep optical conditions stable while the cell is supported only by the patch pipette. Consequently, the patch-clamp technique is not well suited for collecting a large amount of mechanical data. In order to amass a reasonable database, using more stable mechanical conditions and intact cells, the present experimental series was undertaken.

Use of the microchamber has the advantage of providing a stable platform for mechanical measurements. Moreover, when the cell is held and stimulated in the microchamber, its structural integrity is maintained. However, the microchamber partitions the cell both mechanically and electrically. The consequence of electrical partitioning is that one can only estimate the relationship between extracellularly applied command voltages and consequent changes in membrane potential. Furthermore, isolated outer hair cells are depolarized (Ashmore and Meech 1986). Consequently, all microchamber data reflect cell behavior at about -10 to $-30 \mathrm{mV}$ resting membrane potential. In Appendix 2 we show the results of measurements of membrane potentials while command voltages were delivered in the microchamber. These results are useful in interpreting the voltage changes that produced stiffness changes in the present experiments.

Taken together, the results of the whole-cell voltageclamp experiments (He and Dallos 1999) and the present microchamber experiments demonstrate the existence of voltage-dependent stiffness. The biophysical mechanism whereby membrane potential controls the cell's aggregate axial stiffness is as yet obscure, but a model that we proposed recently fairly represents the process (Dallos and He 2000). It was postulated that the conformational change of the molecular motors 


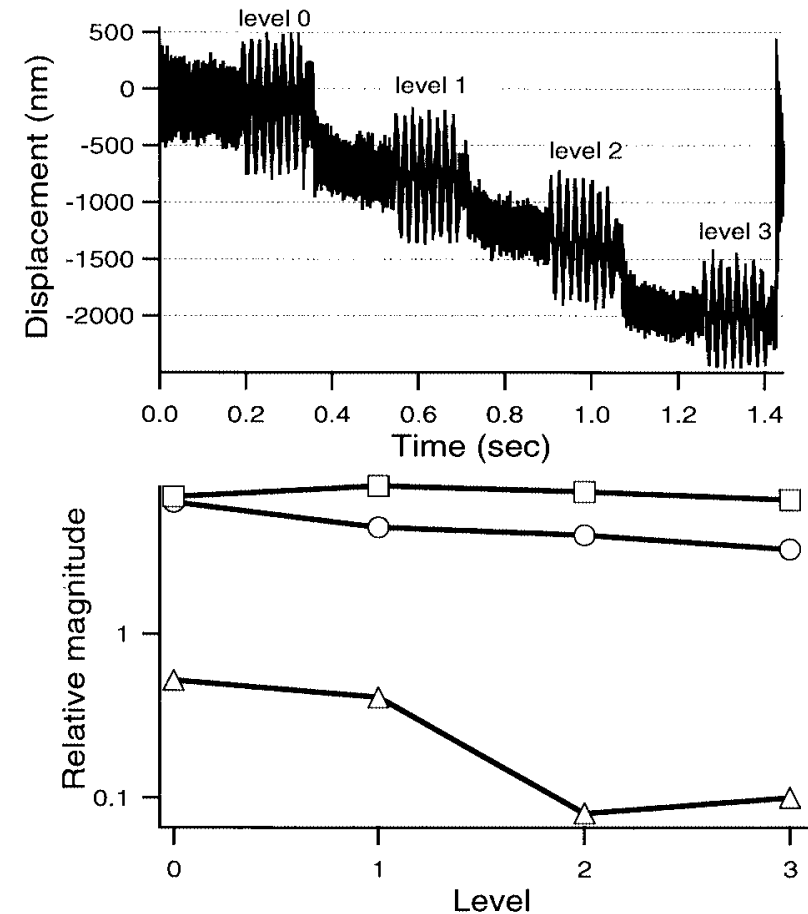

FIG. 11. Examples of effects seen when different degrees of cell compression are used. Each presentation consists of $200 \mathrm{~ms}$ of 2000$\mathrm{Hz}$ fiber motion alone, followed by $200 \mathrm{~ms}$ of fiber motion plus delivery of $200-\mathrm{Hz}$ sinusoidal voltage to the microchamber. From presentation to presentation, the DC load on the cell by the fiber is increased by approximately $500 \mathrm{~nm}$. The top plots show averaged responses for two cells with four levels of compression. The 200-ms
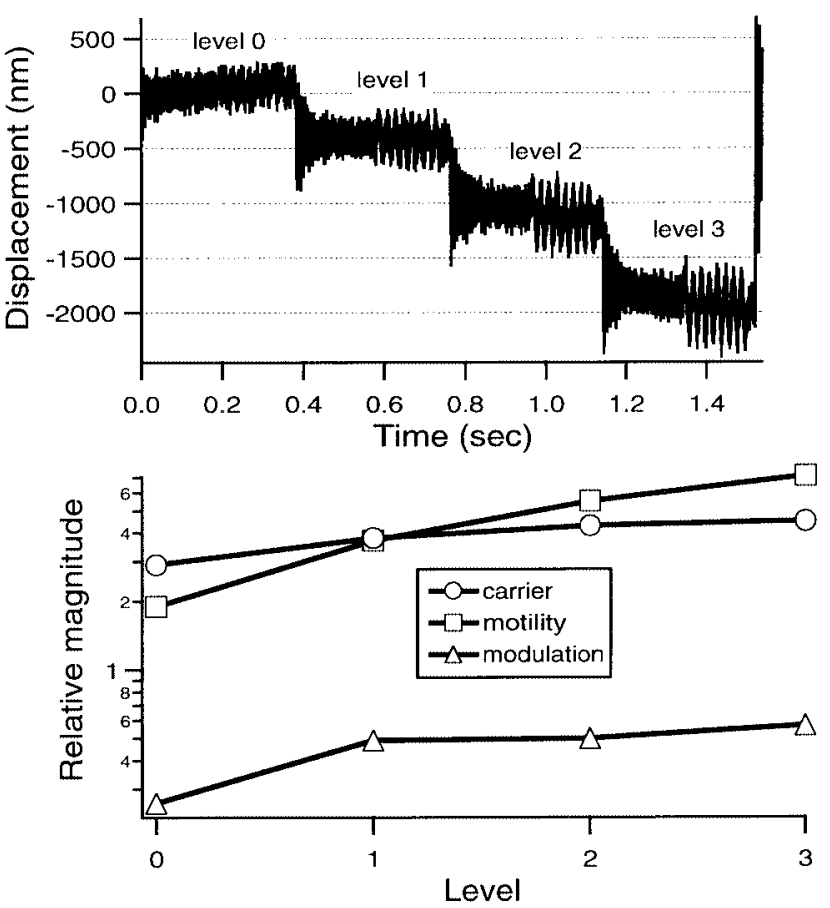

epochs during which both stimuli are present are examined with Fourier analysis. In the bottom panels Fourier components at the fiber-motion frequency, the electromotile response frequency, and at the lower intermodulation frequency $(1800 \mathrm{~Hz})$ are shown as a function of compression. Cell lengths and exclusions: $70 \mu \mathrm{m}, 75 \%$ and $60 \mu \mathrm{m}, 70 \%$. that results in length change is accompanied by stiffness change. In other words, assuming that the molecules have two stable states to which two axial dimensions $X_{\mathrm{L}}$ and $X_{\mathrm{S}}$ (for Long and Short) correspond, they also have two related stiffness states $K_{\mathrm{L}}$ and $K_{\mathrm{S}}$. Transition between the two states is a stochastic function of membrane potential, represented by a Boltzmann process (Dallos et al. 1992, 1993a). We have shown that this simple model accounts for the salient properties of the measured stiffness changes (Dallos and He 2000).

Data obtained with the microchamber and those generated with patch-clamp reveal agreement in the direction of changes. Both sets of data indicate that increased stiffness (reduced response) occurs upon hyperpolarization of the cell, or, in the microchamber, upon hyperpolarization of the measured cell segment. Increased stiffness (reduced response) always occurs during cell extension. Comparisons between the voltage dependence of stiffness measured with patch and microchamber techniques suggest some differences. Figure 4 of $\mathrm{He}$ and Dallos (1999) depict relatively larger changes in stiffness for large hyperpolarization of the cell than for depolarization. In contrast, Figure 5, Figure 6 , and Figure 9 of the present work suggest the opposite behavior. As was pointed out before, the two techniques differ in the cell's mechanical condition and their resting potential. In fact, the functional appearance of the stiffness-membrane potential function [Fig. 4a in He and Dallos (1999)] between -120 and $+20 \mathrm{mV}$ is similar to that seen in the present work. It is likely that we did not reach hyperpolarizations exceeding $-120 \mathrm{mV}$ in the microchamber. Because of the uncertainty of the actual membrane potential during experiments with the microchamber, a numerical relation between stiffness and voltage changes can only be approximated. It was estimated that the average change in stiffness is $0.286 \mathrm{mN} / \mathrm{m}$ per $\mathrm{mV}$ change in membrane potential. This slope is applicable at the isolated cell's depolarized membrane potential.

Our data clearly indicate that voltage-dependent outer hair cell stiffness and voltage-dependent cell length (electromotility: Brownell et al. 1995) are related phenomena. Several such relationships were revealed. Most suggestive is the similar dependence of stiffness and length change upon the command voltage (Figs. 5 and 6 ). This dependence is best fit by a second-order Boltzmann function (even though a firstorder one also provides acceptable fit). The same function can represent both variables (Fig. 6). As measured 
in the microchamber that partitions the cell's electrical impedance, the frequency dependence of electromotility is that of a lead-lag network. In other words, both low- and high-frequency responses are asymptotically constant (Dallos and Evans 1995). This behavior applies to stiffness as well. Since the transition between low- and high-frequency asymptotes is between 10 and $100 \mathrm{~Hz}$, our limited data do not define the former. The transition is, however, clear, as is the existence of the high-frequency asymptote (Fig. 7). Most importantly, the frequency dependence of stiffness and length are essentially the same (Figs. 7 and 8). Finally, we tested the effect of gadolinium on voltagedependent stiffness. This trivalent lanthanide cation is known to reduce electromotility (Santos-Sacchi 1991; Kakehata and Santos-Sacchi 1996). As we show, both electromotility and stiffness change are reduced by external application of $\mathrm{Gd}^{3+}$ (Fig. 10).

The general covariance of stiffness and length changes suggests that they arise from a common mechanism. Standard models of electromotility do not automatically yield stiffness changes. Our "boomerang" model (Dallos and He 2000) is designed to account for both phenomena via a single mechanism. It is also possible to postulate that if in its quiescent state the cell is precompressed, motility may simply be a consequence of stiffness change. This would then render voltage-dependent stiffness the primary mechanism, with length change being an epiphenomenon.

It is interesting to consider how isometric force changes if one considers only motility (no stiffness change) and both motility and stiffness change. The first of these possibilities is the "classic" case (Hallworth 1995; Iwasa and Adachi 1997), that is, the case applicable prior to the discovery of voltage-controlled stiffness. For our example, this is given in Figure 9 as a thin line. The motility-only assumption yields an asymmetrical function with larger changes in the depolarizing direction. The other possibility is also shown in the figure. We used the actual unloaded motility values to produce the curve (heavy line) for the case where both length and stiffness changes are produced directly by voltage, the isometric force is $G(V) K(V)$ (eq. 10). The latter case generates a relatively symmetrical isometric function, but with harder saturation in the depolarizing direction. The small-signal slope (gain) is not significantly different in the two cases. It would be interesting to examine the consequences of these possibilities in a feedback model of cochlear mechanics.

\section{ACKNOWLEDGMENTS}

Work supported by NIH Grant DC00708. We thank G. Emadi for his comments on the manuscript.

\section{APPENDIX 1}

Influence of loading the fiber onto the cell

A systematic study of various effects due to different degrees of initial cell compression is yet to be done. We did measure several response parameters from 16 cells with a four-step loading paradigm. The initial load (level 0) was followed by three additional fiber excursions that compressed the cell by approximately $0.5 \mu \mathrm{m}$ with each consecutive step. During each step a $200-\mathrm{Hz}$ voltage burst was applied to the microchamber while the fiber was continuously moved at $2000 \mathrm{~Hz}$. In Figure 11 the results from two cells are shown. The averaged displacement response is given in the top panels. From the 200-ms segments, during which both electrical and mechanical stimuli were applied, the Fourier components at the frequency of fiber motion $(2000 \mathrm{~Hz})$, electromotility $(200 \mathrm{~Hz})$, and lower sideband frequency $(1800 \mathrm{~Hz})$ were calculated and plotted in the lower panels. The side-band frequency is a representation of intermodulation and, consequently, of stiffness change. The two examples were chosen to demonstrate different behaviors with loading. In one example (Fig. 11a), both the loaded electromotile response and modulation increase with greater compression. In Figure 11b, the opposite behavior is seen, both motility and modulation decrease with increased cell compression. These opposing behaviors have been seen before; Hallworth (1995) has called attention to them in the past. Understanding the mechanism and a detailed description of compression dependence must await systematic investigation. It can be said, however, that under both patterns of compression dependence in Figure 11, nonlinear (voltage-dependent) stiffness was present. Our usual static compression of the cells by the fiber during the experiments in this project can be best approximated by the level-0 state. These demonstrations indicate that while quantitative changes in voltage-dependent stiffness could be expected with different preloading, the phenomenon itself is qualitatively robust.

\section{APPENDIX 2}

\section{Relationship between command voltage and membrane potential}

As noted before, the relationship between command voltage and voltage drop across the cell's basolateral membrane can at best be estimated (Dallos et al. 1991). In order to provide a better estimate, we performed an experiment on nine cells. The cells were drawn into the microchamber as usual (Fig. 1), but we also engaged a whole-cell patch configuration in order to 


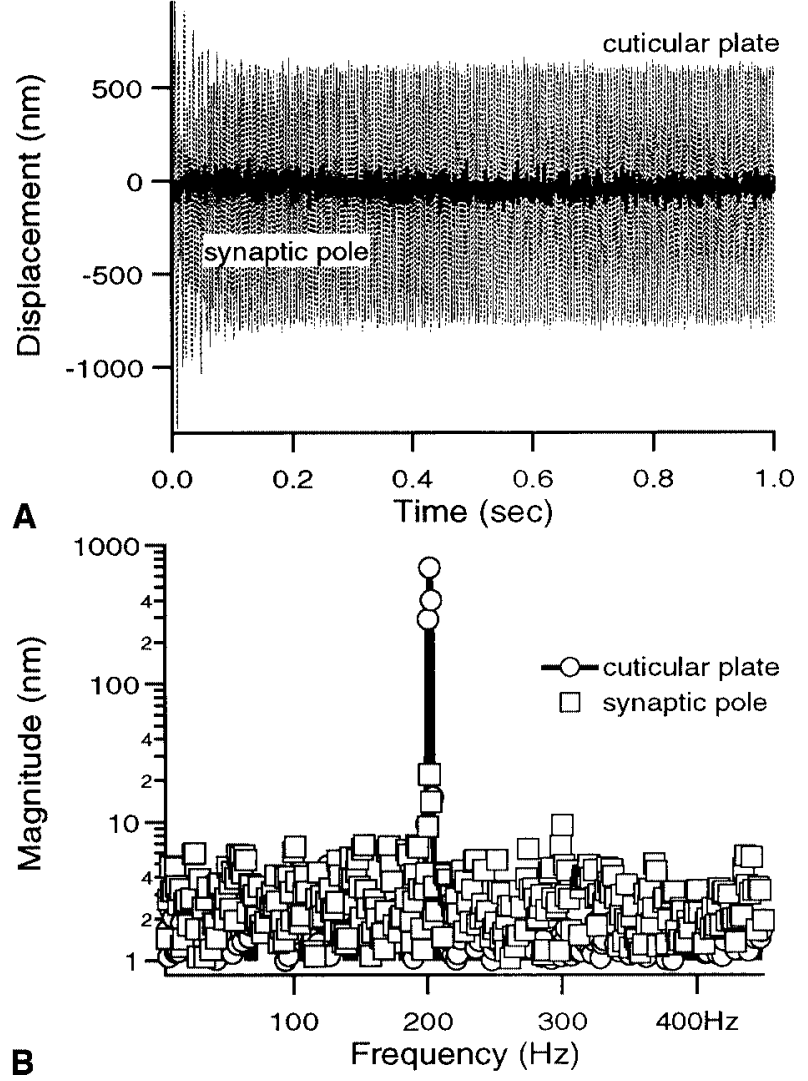

FIG. 12. Example of the relationship between displacements of cuticular plate and synaptic pole when the displacement is elicited by the $200-\mathrm{Hz}$ sinusoidal motion of the fiber (as in Fig. 1a). (a) Responses as a function of time. (b) Fourier transforms of the above waveforms.

measure the cell's membrane potential (Huang and Santos-Sacchi 1993; He et al. 1997). We found that the relationship between membrane potential and command voltage was generally nonlinear, particularly for large negative command voltages. The details of these experiments will be published elsewhere. However, in order to help interpret the present work, it is mentioned here that around zero command voltage, the slope of the membrane potential vs. command voltage function averaged $0.115 \mathrm{mV} / \mathrm{mV}$. The range of command voltages in this experiment, between -280 and $+280 \mathrm{mV}$, corresponded to an average membrane potential range of -20.8 to $+14.5 \mathrm{mV}$. We found the average sensitivity of the motile response to be $34.5 \mathrm{~nm} / \mathrm{mV}$.

\section{APPENDIX 3}

\section{Displacement of the cell's two poles}

In order to test for the possibility that the fiber forces the cell to move in and out of the microchamber, we measured the displacement of both the excluded cuticular plate and the included synaptic pole. The cells were placed in the microchamber as during the actual experiments; between 15 and $25 \%$ of their length was included. The slit was positioned over the apical and basal extremes of the cell and sequential calibrations and measurements were performed. The fiber was moved at a frequency of $200 \mathrm{~Hz}$. We show an example in Figure 12. Figure 12a provides the averaged waveform for both displacement responses, while Figure 12b gives their spectra. In this case the cuticular plate, which was directly displaced by the fiber, was moving some 30 times more than the included synaptic pole. The average ratio measured for five cells was 26 $\mathrm{dB}$. We conclude that if there is any slippage of the cell at the microchamber's orifice, it is very small. It is also noted that some displacement of the synaptic pole is expected in this experimental situation even with no slippage. As the excluded cell segment is compressed and expanded by the fiber, the cell's internal pressure changes. Such pressure change should produce displacement at the opposite pole of the cell (Dallos et al. 1993b).

\section{REFERENCES}

Allen JB. Modeling the noise damaged cochlea. Dallos P, Geisler CD Matthews JW, Ruggero MA, Steele CR. The mechanics and biophysics of hearing. Springer-Verlag, Berlin, 324-332, 1990.

ASHMORE JF, MEECH RW. Ionic basis of membrane potential in outer hair cells of guinea pig cochlea. Nature. 322:368-371, 1986.

AsHMORE JF. A fast motile response in guinea pig outer hair cells: the cellular basis of the cochlear amplifier. J. Physiol. London. 388:323-347, 1987.

Brownell WE, BADER CR, BERTRAND D, DE RIBAuPIERRE Y. Evoked mechanical responses of isolated cochlear hair cells. Science. 227:194-196, 1985.

Dallos P. The active cochlea. J. Neurosci. 12:4575-4585, 1992.

Dallos P. Introduction and overview. Dallos P, Popper AN, FAY R. The Cochlea. Springer-Verlag, New York, 435-502, 1996.

Dallos P, Evans BN. High frequency motility of outer hair cells and the cochlear amplifier. Science. 267:2006-2009, 1995.

Dallos P, He DZZ. Models of outer hair cell stiffness and motility. WADA H, TAKASAKA T. Recent Developments in Auditory Mechanics in press, 2000.

Dallos P, Hallworth R, Evans BN. Nature of the motor element in electrokinetic shape changes of cochlear outer hair cells. Nature. 350:155-157, 1991.

Dallos P, Hallworth R, Evans BN. Stochastic theory of outer hair cell electromotility. Cazals Y, Horner K, Demany L. Auditory physiology and perception Pergamon Press Oxford 35-44, 1992.

Dallos P, Hallworth R, Evans BN. Theory of electrically driven shape changes of cochlear outer hair cells. J. Neurophys. 70:299323, 1993a.

Dallos P, He ZZ, Evans BN, Clark B. Dynamic characteristics of outer hair cell motility. DUIFHUIS H, HORST JW, van DIJK P, vaN NetTen SM. Biophysics of hair cell sensory systems. World Scientific, Singapore, 167-174, 1993b.

Dallos P, He DZZ, Lin X, Sziklai I, Mehta S, Evans BN. Acetylcholine, outer hair cell electromotility, and the cochlear amplifier. J. Neurosci. 17:2212-2226, 1997. 
Evans BN, Hallworth R, Dallos P. Asymmetries of motile responses of outer hair cells in simulated in vivo conditions. WILSON JP, KeMP DT. Cochlear mechanisms. Plenum Press London 205-206, 1989b.

Evans BN, Hallworth R, DAllos P. Outer hair cell electromotility: the sensitivity and vulnerability of the DC component. Hear. Res. 52:288-304, 1991

FORGE A. Structural features of the lateral walls in mammalian cochlear outer hair cells. Cell Tissue Res. 265:473-483, 1991.

Frank G, Werner Hemmert W, Gummer AW. Limiting dynamics of high-frequency electromechanical transduction of outer hair cells. Proc. Natl. Acad. Sci. USA. 96:4420-4425, 1999.

Frolenkov GI, Belyantseva IA, Kachar B. Electromotility influences the axial stiffness of the outer hair cells. Abstr. ARO. 21:64, 1998.

GALE JE, ASHMORE JF. Charge displacement induced by rapid stretch in the basolateral membrane of the guinea-pig outer hair cell. Proc. R. Soc. Lond. Biol. 255:233-249, 1995.

Gitter AH, Rudert M, Zenner HP. Forces involved in length changes of cochlear outer hair cells. Pflügers Arch. 424:9-14, 1993.

GUINAN JJJr. Physiology of olivocochlear efferents. DALlos P, POPPER AN, FAY RR. The cochlea. Springer-Verlag, New York, 435-502, 1996.

HAllworth R. Passive compliance and active force generation in the guinea pig outer hair cell. J. Neurophys. 74:2319-2328, 1995.

HALLWORTH R. Modulation of outer hair cell compliance and force by agents that affect hearing. Hear. Res. 114:204-212, 1997.

Hamill OP, Marty A, Neher E, Sakmann B, Sigworth FJ. Improved patch-clamp techniques for high-resolution current recording from cells and cell-free membrane patches. Pflügers Arch. 391:85$100,1981$.

He DZZ, Evans BN, Dallos P. Voltage-dependent DC motility in isolated outer hair cells. Abstr. ARO. 17:291, 1994.

HE DZZ, Lin X, DALlos P. Mechanical properties of isolated outer hair cells. Abstr. ARO. 20:74, 1997.

He DZZ, Dallos P. Somatic stiffness of cochlear outer hair cells is voltage-dependent. Proc. Natl. Acad. Sci. USA. 96:8223-8228, 1999.

Hemmert W, Schauz C, Zenner HP, Gummer AW. Force generation and mechanical impedance of outer hair cells. LEWIS ER, LONG GR, LEAKe PA, NARINS PM, STEele CR. Diversity in auditory mechanics World Scientific, Singapore, 531-537, 1997.

Holley MC. Outer hair cell motility. Dallos P, PopPer AN, FAy RR. The cochlea. Springer-Verlag, New York, 386-434, 1996.

Holley MC, Ashmore JF. On the mechanism of high frequency force generator in outer hair cells isolated from guinea pig cochlea. Proc. R. Soc. B Biol. Sci. 232:413-429, 1988.

Housley GD, CONNOR BJ, RaYBould NP. Purinergic modulation of outer hair cell electromotility. Flock A, OTtOSON D, UlfENDAHL M. Active hearing. Pergamon Press, London, 221-238, 1995.

HuANG G, SANTOS-SACCHI J. Mapping the distribution of outer hair cell motility voltage sensor by electrical amputation. Biophys. J. 65:2228-2236, 1993.

IWASA KH. Effect of stress on the membrane capacitance of the auditory outer hair cell. Biophys. J. 65:492-498, 1993.

IWASA KH, ADACHI M. Force generation in the outer hair cells of the cochlea. Biophys. J. 73:546-555, 1997.

KAKEHATA S, SANTOS-SACCHI J. Membrane tension directly shifts voltage dependence of outer hair cell motility and associated gating charge. Biophys. J. 68:2190-2197, 1995.

KAKEHATA S, SANTOS-SACCHI J. Effects of salicylate and lanthanides on outer hair cell motility and associated gating charge. J. Neurosci. 16:4881-4889, 1996.

Kalinec F, Holley M, Iwasa K, Lim D, KaChar BA. Membrane based force generation mechanism in auditory sensory cells. Proc. Natl. Acad. Sci. USA. 89:8671-8675, 1992.

Kolston PJ, De Boer E, Viergever MA, Smoorenburg GF. What type of force does the cochlea amplifier produce? J. Acoust. Soc. Am. 88:1794-1801, 1990.

Mountain DC, HubBard AE. A piezoelectric model of outer hair cell function. J. Acoust. Soc. Am. 95:350-354, 1994.

Oghalai JS, Patel AA, Nakagawa T, Brownell WE. Fluorescenceimaged microdeformation of the outer hair cell lateral wall. J. Neurosci. 18:48-58, 1998.

Russell I, ScHauz C. Salicylate ototoxicity: Effects on the stiffness and electromotility of outer hair cells isolated from the guinea pig cochlea. Auditory Neurosci. 1:309-319, 1995.

SANTOS-SACCHI J. Reversible inhibition of voltage-dependent outer hair cell motility and capacitance. J. Neurosci. 11:3096-3110, 1991.

SANTOS-SACCHI J, Dilger JP. Whole cell currents and mechanical responses of isolated outer hair cells. Hear. Res. 35:143-150, 1988.

SEWELL WF. Neurotransmitters and synaptic transmission. DALlos P, Popper AN, FAY RR. The cochlea. Springer-Verlag, New York, 503-533, 1996.

Shehata WE, Brownell WE, Dieler R. Effects of salicylate on shape, electromotility and membrane characteristcs of isolated outer hair cells from guinea pig cochlea. Acta Otolaryngol. (Stockh.) 111:707-718, 1991.

Slepecky N, Dallos P, Popper AN, FAy RR. The cochlea. SpringerVerlag, New York, 44-129, 1996.

Spector AA, Brownell WE, Popel AS. Elastic properties of the composite outer hair cell wall. Ann. Biomed. Eng. 26:157-165, 1998.

STRELIOFF D, Flock A. Stiffness of sensory-cell hair bundles in the isolated guinea pig cochlea. Hear. Res. 15:19-28, 1984.

Tolomeo JA, STEELE CR. A dynamic model of cell motility including intracellular and extracellular viscosity. J. Acoust. Soc. Am. 103:524-534, 1998.

Tolomeo JA, Steele CR, Holley MC. Mechanical properties of the lateral cortex of mammalian auditory outer hair cells. Biophys. J. 71:421-429, 1996.

Tunstall MJ, Gale JE, Ashmore JF. Action of salicylate on membrane capacitance of outer hair cells from the guinea-pig cochlea. J. Physiol. (Lond.) 485:739-752, 1995.

Ulfendahl M, Chan E, McConnaughey WB, Prost-Domasky S, ELSON EL. Axial and transverse stiffness measures of cochlear outer hair cells suggest a common mechanical basis. Pflügers Arch. 436:9-15, 1998.

WEISS TF. Bidirectional transduction in vertebrate hair cells: A mechanism for coupling mechanical and electrical processes. Hear. Res. 7:353-360, 1982.

ZAO H-B, SANTOS-SACCHI J. Auditory collusion and a coupled couple of outer hair cells. Nature. 399:359-362, 1999.

ZENner HP, GiTter AH, Rudert M, ERnst A. Stiffness, compliance, elasticity and force generation of outer hair cells. Acta Otolaryngol. (Stockh.) 112:248-253, 1992.

ZWISLOCKI JJ, CEFARATTI LK. Tectorial membrane II: Stiffness measurements in vivo. Hear. Res. 42:211-228, 1989. 